\title{
1 Constraints on the formation and diagenesis of 2 phosphorites using carbonate clumped isotopes
}

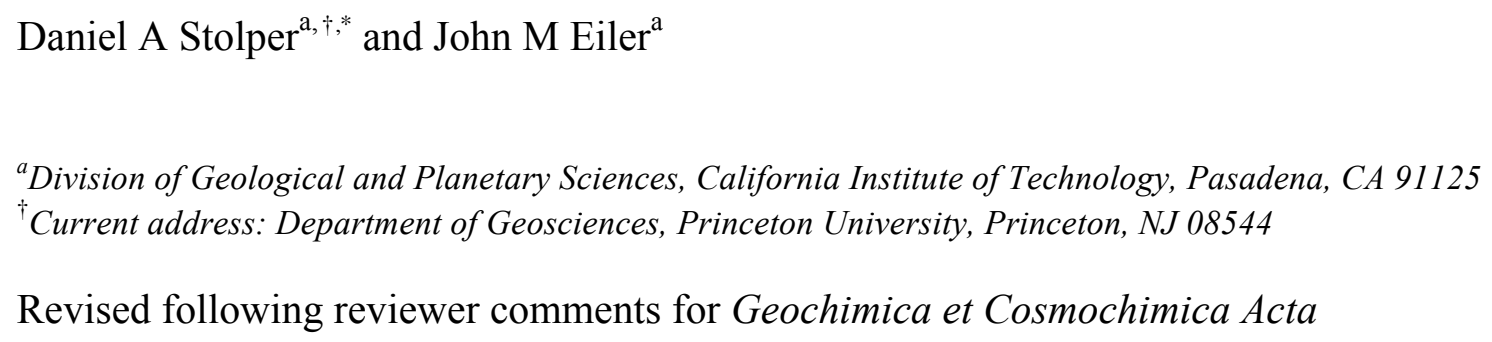

Abstract: The isotopic composition of apatites from sedimentary phosphorite deposits has been used previously to reconstruct ancient conditions on the surface of the earth. However, questions remain as to whether these minerals retain their original isotopic composition or are modified during burial and lithification. To better understand how apatites in phosphorites form and are diagenetically modified, we present new isotopic measurements of $\delta^{18} \mathrm{O}$ values and clumped-isotope-based $\left(\Delta_{47}\right)$ temperatures of carbonate groups in apatites from phosphorites from the past 265 million years. We compare these measurements to previously measured $\delta^{18} \mathrm{O}$ values of phosphate groups from the same apatites. These results indicate that the isotopic composition of many of the apatites do not record environmental conditions during formation but instead diagenetic conditions. To understand these results, we construct a model that describes the consequences of diagenetic modification of phosphorites as functions of the environmental conditions (i.e., temperature and $\delta^{18} \mathrm{O}$ values of the fluids) during initial precipitation and subsequent diagenesis. This model captures the basic features of the dataset and indicates that clumped-isotope-based temperatures provide additional quantitative constraints on both the formational environment of the apatites and subsequent diagenetic modification. Importantly, the combination of the model with the data indicates that the $\delta^{18} \mathrm{O}$ values and clumped-isotope temperatures recorded by phosphorites do not record either formation or diagenetic temperatures, but rather represent an integrated history that includes both the formation and diagenetic modification of the apatites.

\footnotetext{
* Corresponding author: Division of Geological and Planetary Sciences, California Institute of Technology, Pasadena, CA 91125, dstolper@ caltech.edu
} 


\section{Introduction}

Paleotemperature reconstructions are a key area of research in Earth science. Although many geochemical tools exist to make these reconstructions, an early and still widely used technique is based on oxygen-isotope analyses of carbonate-bearing minerals like calcite and aragonite (McCrea, 1950; Epstein et al., 1953). Oxygen-isotope-based reconstructions (represented using $\delta$ notation ${ }^{1}$ ) of mineral formation temperatures requires independent knowledge of the isotopic composition the formational fluids. Additionally, samples cannot have been isotopically altered after deposition. Problematically, constraints on the isotopic composition of the original formational fluids as well as the isotopic integrity of carbonate-bearing minerals over geological time are old, persistent, controversial, and unresolved issues (e.g., Degens and Epstein, 1962; Killingley, 1983; Muehlenbachs, 1986; Veizer et al., 1986; Schrag et al., 1992, 1995; Land, 1995; Veizer et al., 1997; Lécuyer and Allemand, 1999; Veizer et al., 1999; Kasting et al., 2006; Jaffrés et al., 2007; Came et al., 2007; Trotter et al., 2008; Finnegan et al., 2011; Veizer and Prokoph, 2015).

With foresight on these potential concerns, Urey et al. (1951) suggested that the oxygenisotope composition of apatite, which is a function temperature (Urey, 1947; Longinelli and Nuti, 1973; Kolodny et al., 1983), could be used to complement and independently test calcite- and aragonite-based $\delta^{18} \mathrm{O}$ temperature reconstructions. Furthermore, $\mathrm{PO}_{4}^{3-}$ groups in apatite have been suggested to be more resistant to post-depositional isotopic exchange than $\mathrm{CO}_{3}{ }^{2-}$ groups in calcite and aragonite (Kolodny et al., 1983; Shemesh et al., 1983; Longinelli et al., 2003). Thus, they are sometimes preferred for isotope-based temperature reconstructions

Apatites are also of interest for isotopic studies as they can contain structural $\mathrm{PO}_{4}{ }^{3-}$ and $\mathrm{CO}_{3}{ }^{2-}$ groups, both of which can be independently analyzed for $\delta^{18} \mathrm{O}$ (Tudge, 1960; Longinelli and Nuti, 1968; Kolodny and Kaplan, 1970; Longinelli and Nuti, 1973; Shemesh et al., 1983; Shemesh et al., 1988). Such measurements are denoted as $\delta^{18} \mathrm{O}_{\mathrm{PO}}$ and $\delta^{18} \mathrm{O}_{\mathrm{CO} 3}$ respectively. When combined, these allow for the calculation of formation temperatures that are independent of the isotopic composition of the water in which the apatite formed (Shemesh et al., 1983).

Apatite from phosphatic brachiopod shells (e.g., Lécuyer et al., 1996; Lécuyer et al., 1998; Wenzel et al., 2000), teeth and bones (e.g., Kolodny et al., 1983; Luz et al., 1984a; Longinelli, 1984; Kolodny and Luz, 1991; Ayliffe et al., 1994; Sharp et al., 2000; Kohn and Cerling, 2002; Eagle et al., 2011), conodonts (e.g., Luz et al., 1984b; Wenzel et al., 2000; Trotter et al., 2008; Sun et al., 2012), and authigenic phosphorite deposits (Longinelli and Nuti, 1968; Shemesh et al., 1983; Shemesh et al., 1988; Ayliffe et al., 1992; Hiatt and Budd, 2001; Jaisi and Blake, 2010) have all been used for paleotemperature reconstructions. Phosphorites, which are the focus of this study, were

\footnotetext{
${ }^{1} \delta=\left(\mathrm{R}_{\text {sample }} / \mathrm{R}_{\text {standard }}-1\right) * 1000$ where $\mathrm{R}=\left[{ }^{13} \mathrm{C}\right] /\left[{ }^{12} \mathrm{C}\right]$ for carbon isotopes and $\left[{ }^{18} \mathrm{O}\right] /\left[{ }^{16} \mathrm{O}\right]$ for oxygen isotopes. For carbon isotopes, samples are referenced to VPDB and for oxygen isotopes, to VSMOW.
} 
some of the earliest apatite samples used for $\delta^{18} \mathrm{O}_{\mathrm{PO} 4}$-based reconstructions of ancient surface conditions (Longinelli and Nuti, 1968; Shemesh et al., 1983). These studies showed that the $\delta^{18} \mathrm{O}_{\mathrm{PO} 4}$ values of Phanerozoic phosphorite apatites decrease with increasing depositional age, mirroring a similar decline in $\delta^{18} \mathrm{O}$ values of carbonates. Due to the perceived resistance of $\mathrm{PO}_{4}{ }^{3-}$ groups to post-depositional isotopic modification, Shemesh et al. (1983) argued that the signal of decreasing $\delta^{18} \mathrm{O}_{\mathrm{PO} 4}$ reflected changing environmental conditions. This requires that either the ocean tens to hundreds of millions of years ago was significantly (e.g., $\sim 10+{ }^{\circ} \mathrm{C}$ ) warmer than today, or that the $\delta^{18} \mathrm{O}$ value of the ocean was lower than today (by multiple per mil), or some combination of the two effects).

However, after these initial studies, it was recognized that apatite $\mathrm{PO}_{4}{ }^{3-}$ oxygen is not impervious to isotope exchange after mineral formation (Shemesh et al., 1988; McArthur and Herczeg, 1990; Kastner et al., 1990; Ayliffe et al., 1994; Kolodny et al., 1996; Sharp et al., 2000; Wenzel et al., 2000; Zazzo et al., 2004). For example, microbially mediated reactions can catalyze the exchange of oxygen isotopes between phosphate and water (Blake et al., 1997; Zazzo et al., 2004). Thus, a critical question for all paleoclimatedriven studies of apatites that employ oxygen isotopes is do measured $\delta^{18} \mathrm{O}$ values reflect original mineral formation temperatures? Or, alternatively, do they reflect some other aspect of the sample's diagenetic and subsequent geological history? This is a particularly troublesome question for studies of phosphorites because there are no agreed upon geochemical or petrographic criteria that can be used to establish whether or not a given sample has been diagenetically altered (Shemesh et al., 1983; Shemesh et al., 1988; Shemesh, 1990).

In order to contribute to the understanding of how and under what conditions sedimentary apatites form and are modified during burial and lithification, we made 'clumped-isotope' measurements of carbonate groups in phosphorite apatite with depositional ages from near modern to 265 million years old and compared them to measured $\delta^{18} \mathrm{O}_{\mathrm{CO} 3}$ and $\delta^{18} \mathrm{O}_{\mathrm{PO} 4}$ values on the same samples. Carbonate clumped-isotope measurements quantify the amount of multiply isotopically substituted (clumped) carbonate groups that generate mass-47 $\mathrm{CO}_{2}$ molecules $\left({ }^{13} \mathrm{C}^{16} \mathrm{O}^{18} \mathrm{O},{ }^{12} \mathrm{C}^{17} \mathrm{O}^{18} \mathrm{O},{ }^{13} \mathrm{C}^{17} \mathrm{O}_{2}\right.$ ) during acid digestion (Ghosh et al., 2006). At isotopic equilibrium, clumped isotopologues are enriched compared to a random distribution of isotopes amongst all isotopologues. Importantly, the size of the enrichment is a unique function of temperature and thus can be used for paleotemperature reconstructions (e.g., Wang et al., 2004; Schauble et al., 2006; Eiler, 2007; Dennis and Schrag, 2010; Eiler, 2011; Eiler, 2013; Zaarur et al., 2013; Defliese et al., 2015; Kluge et al., 2015). Clumped-isotope abundances of carbonates are quantified with the symbol $\Delta_{47}$ (footnote 2), which is a monotonic function of mineral formation temperature (e.g., Ghosh et al., 2006; Dennis and Schrag, 2010; Zaarur et al., 2013; Defliese et al., 2015; Kluge et al., 2015).

Because clumped-isotope temperatures are independent of the isotopic composition of the

\footnotetext{
${ }^{2} \Delta_{47}=\left(\left[{ }^{47} \mathrm{R}\right]\left[{ }^{47} \mathrm{R}^{*}\right]-1\right) \times 1000$ where ${ }^{47} \mathrm{R}=\left[{ }^{13} \mathrm{C}^{16} \mathrm{O}^{18} \mathrm{O}+{ }^{12} \mathrm{C}^{17} \mathrm{O}^{18} \mathrm{O}+{ }^{13} \mathrm{C}^{17} \mathrm{O}_{2}\right] /\left[{ }^{12} \mathrm{C}^{16} \mathrm{O}_{2}\right]$ and * denotes the random distribution.
} 
waters from which minerals form, such measurements can provide new constraints on a 119 sample's chemical and physical formational conditions and geological history. This 120 includes allowing for the calculation of the isotopic composition of the formation waters (e.g., Came et al., 2007; Finnegan et al., 2011; Ferry et al., 2011; Petersen and Schrag, 2015). Here we explore the additional constraints clumped-isotope temperatures can provide on the conditions of phosphorite formation and modification when combined with $\delta^{18} \mathrm{O}$ measurements of both structural phosphate and carbonate groups. Because both the temperature based on the $\delta^{18} \mathrm{O}_{\mathrm{PO} 4}-\delta^{18} \mathrm{O}_{\mathrm{CO} 3}$ fractionation and that based on the clumped-isotope technique can be measured within a single phase, one mineral can yield two independent constraints on a sample's formation temperature. These temperatures should reflect either the conditions under which phosphorites formed or were later modified. For example, if the temperatures disagree, it would likely indicate either nonequilibrium precipitation or diagenesis post formation. Such a strategy was used by Eagle et al. (2011) to distinguish pristine fossil samples of dinosaur teeth from those diagenetically altered. Here, we provide a framework for the quantitative interpretation of the meaning of $\delta^{18} \mathrm{O}_{\mathrm{PO} 4}-\delta^{18} \mathrm{O}_{\mathrm{CO} 3}$ fractionations vs. clumped-isotope measurements, and a critical examination into the insights such a 'dual-thermometer' approach can provide.

Specifically, we demonstrate that measurements of clumped-isotope temperatures in combination with $\delta^{18} \mathrm{O}_{\mathrm{PO} 4}$ and $\delta^{18} \mathrm{O}_{\mathrm{CO} 3}$ measurements allow for both the identification of samples that have been diagenetically modified as well as the 'style' of that diagenesis: e.g., open, water-buffered vs. closed-system diagenesis and the extent of diagenetic overprinting. We show that many samples yield clumped-isotope temperatures that are distinct from the temperatures inferred solely using $\delta^{18} \mathrm{O}_{\mathrm{PO} 4}$ and $\delta^{18} \mathrm{O}_{\mathrm{CO} 3}$ values. We suggest that this disagreement is caused by different oxygen-isotope-exchange rates of $\mathrm{PO}_{4}{ }^{3-}$ and $\mathrm{CO}_{3}{ }^{2-}$ groups with water during diagenesis. Such differing rates would allow a mineral, during diagenesis, to yield phosphate and carbonate groups out of equilibrium with each other.

To explore this hypothesis quantitatively, we develop a model to describe the waterbuffered diagenesis of $\delta^{18} \mathrm{O}_{\mathrm{PO} 4}, \delta^{18} \mathrm{O}_{\mathrm{CO} 3}$, and $\Delta_{47}$ values in apatite and fit the model to the measured data. This model yields the insight that inferred clumped-isotope-based temperatures of the diagenetically modified apatites do not represent the temperature at which diagenesis took place, as is sometimes assumed in clumped-isotope studies. Instead the clumped-isotope temperatures reflect the integrated history of the mineral from formation through diagenesis. This inference is then placed in the context of a qualitative model of apatite growth and modification in phosphorites, informed by commonly observed fabrics of such rocks. We note that the data and models presented here were originally presented in a graduate Ph.D. thesis (Stolper, 2014). Additionally, a recent study reported three measurements of clumped-isotope temperatures of apatites from the Monterey Formation phosphorite (Bradbury et al., 2015), but did not include $\delta^{18} \mathrm{O}_{\mathrm{PO} 4}$ measurements. We comment on these results in the context of the samples measured in this study below. 


\section{Materials and Methods}

\subsection{Materials}

Phosphorite samples measured in this study are listed in Table 1 and are the same as those used in Shemesh et al. (1983) and Shemesh et al. (1988), except for NBS 120C. All $\delta^{18} \mathrm{O}_{\mathrm{PO} 4}$ values are from Shemesh et al. (1988) and were measured as $\mathrm{BiPO}_{4}$, except NBS 120C, which was analyzed as $\mathrm{Ag}_{3} \mathrm{PO}_{4}$ (Pucéat et al., 2010; Lécuyer et al., 2013). Because there is an apparent offset between $\delta^{18} \mathrm{O}_{\mathrm{PO}}$ values measured using $\mathrm{BiPO}_{4}$ vs. $\mathrm{Ag}_{3} \mathrm{PO}_{4}$ (Pucéat et al., 2010; Lécuyer et al., 2013), we converted NBS 120C to the $\mathrm{BiPO}_{4}$-method 'reference frame'. We did this by assuming a $\delta^{18} \mathrm{O}_{\mathrm{PO} 4}$ value of $20 \%$ for NBS $120 \mathrm{~B}$ when measured using the $\mathrm{BiPO}_{4}$ method (Pucéat et al., 2010; Lécuyer et al., 2013) and an offset of $0.3 \%$ between NBS $120 \mathrm{~B}$ and $120 \mathrm{C}$, which was found using an $\mathrm{Ag}_{3} \mathrm{PO}_{4}$ method (Lécuyer et al., 2013). This results in a $\delta^{18} \mathrm{O}$ value of $20.3 \%$ for NBS $120 \mathrm{C}$ in the $\mathrm{BiPO}_{4}$ method reference frame.

\subsection{Sample preparation}

All measured phosphorite samples were previously powdered before delivery to the Caltech laboratories. Grain sizes were not measured. Each sample was first treated with $3 \% \mathrm{H}_{2} \mathrm{O}_{2}$ at room temperature for 4 hours to remove any organic contaminants and then washed 3 times in deionized (DI) water. Samples were subsequently treated with buffered acetic acid $(0.1 \mathrm{M}, \mathrm{pH}=4.5)$ for 48 hours to remove exogenous carbonate minerals (i.e., carbonate not dissolved in the phosphate lattice), washed 3 times in deionized water, then dried overnight in a $70^{\circ} \mathrm{C}$ oven. This procedure follows those described in Eagle et al. (2010). We note that based on experiments with apatites in the lab, heating samples overnight at $70^{\circ} \mathrm{C}$ is unlikely to alter measured clumped-isotope temperatures. For example, holding samples at $\sim 400^{\circ} \mathrm{C}$ for a week does not, within analytical error, alter clumped-isotope compositions of igneous apatites (Stolper and Eiler, 2015).

\subsection{Isotopic measurements}

Measurements of $\delta^{13} \mathrm{C}_{\mathrm{CO} 3}$ (the $\delta^{13} \mathrm{C}$ value of carbonate groups dissolved in apatite) and $\delta^{18} \mathrm{O}_{\mathrm{CO} 3}$ (Table 1) and $\Delta_{47}$ (Table 2) values of carbonate groups dissolved in apatite were made on $\mathrm{CO}_{2}$ evolved from the acid digestion of phosphates at Caltech. Samples were digested for $20 \mathrm{~min}$ in a $90^{\circ} \mathrm{C}$ stirred acid bath with $104 \%$ phosphoric acid on two nearly identical automated extraction lines as described in Passey et al. (2010) and Eagle et al. (2010). The isotopic composition of $\mathrm{CO}_{2}$ was measured on two separate mass spectrometers following procedures outlined in Eiler and Schauble (2004) and Huntington et al. (2009). Note that some samples, but not all, were measured using both extraction lines and mass spectrometers. $\delta^{13} \mathrm{C}$ and $\delta^{18} \mathrm{O}$ values of samples were determined through comparison to a gas with a known isotopic composition using an ioncorrection algorithm in the Isodat software program (Huntington et al., 2009) and standardized to the VPDB scale for carbon-isotope measurements and VSMOW for oxygen-isotope measurements. Carbonate $\delta^{18} \mathrm{O}$ values were calculated from the $\mathrm{CO}_{2}$ values assuming that the isotopic fractionation factor $\left({ }^{18} \mathrm{R}_{\mathrm{CaCO} 3} /{ }^{18} \mathrm{R}_{\mathrm{CO} 2}\right)$ for phosphoric acid 
digestion at $90^{\circ} \mathrm{C}$ is 1.00821 (Swart et al., 1991). We thus assume that carbonate dissolved in apatite has the same oxygen-isotope acid-digestion fractionation factor as calcite. We note that different acid-digestion fractionation factors have been suggested for hydroxyapatite from fossil material (Passey et al., 2007) as compared to those used for calcite. Using these apatite-specific fractionation factors would shift our measured $\delta^{18} \mathrm{O}$ values of carbonate groups in apatite to values $\sim 0.5$ to $1 \%$ o lower than reported here. However, we do not use these alternative fractionation factors as the differences they introduce are not significant to the study here nor have they been studied for fluroapatites (the mineralogical form of apatites in phosphorites).

$\Delta_{47}$ values are reported in the 'absolute' reference frame, or as it is sometimes referred to, the 'carbon dioxide equilibrium scale' of Dennis et al. (2011). This reference frame was generated by measuring gases isotopically equilibrated with water at $25^{\circ} \mathrm{C}$ and gases heated in quartz glass tubes at $1000^{\circ} \mathrm{C}$. An acid digestion fractionation factor of $0.092 \%$ (Henkes et al., 2013) was used to convert measured $\Delta_{47}$ values of $\mathrm{CO}_{2}$ extracted from carbonate apatite at $90{ }^{\circ} \mathrm{C}$ to the $25^{\circ} \mathrm{C}$ acid-digestion reference frame used for interlaboratory comparisons and clumped-isotope temperature calculations. The choice of the acid-digestion correction is discussed in section A1.

All phosphorite samples were run at least four times across at least three different analytical sessions, except for NBS 120C. NBS 120C samples were run in the same analytical session before our lab began regularly running $25^{\circ} \mathrm{C}$ equilibrated gases in order to report samples in the absolute reference frame. We calculated the absolute reference frame values for measurements of this sample following the procedures for a 'secondary' absolute reference frame, as described in Dennis et al. (2011).

Phosphorite samples were screened for possible contamination that might result in isobaric interferences at mass 47 by measuring $\Delta_{48}$ values, where $\Delta_{48}=\left({ }^{48} \mathrm{R} /{ }^{48} \mathrm{R}^{*}-1\right) \mathrm{x}$ 1000 as defined and described in Huntington et al. (2009). All $\Delta_{48}$ values for data reported here are less than $0.6 \%$ (Table 2 ), which is below the commonly applied threshold value of $\sim 1 \%$ for the rejection of analyses (e.g., Henkes et al., 2013). For comparison, the inorganic carbonate standards measured in this study have $\Delta_{48}$ values that range from 0.4 to $0.6 \%$. These values are similar to the theoretical values expected for internal isotopic equilibrium for temperatures between 25 to $300^{\circ} \mathrm{C}$, which are 0.2 to $0.3 \%$ respectively (Guo et al., 2009).

Precision and accuracy for analyses of crystalline carbonate standards analyzed concurrently with phosphates were evaluated by running two standards, a Carrara marble in-house standard and travertine in-house standard (TV01), in every analytical session. Average $\Delta_{47}, \delta^{18} \mathrm{O}$ and $\delta^{13} \mathrm{C}$ values and precisions for these standard are given in Tables $\mathrm{A} 1$ and A2. Isotopic values for standards were found to be accurate: all averages are within 1 standard deviation of long term in-house values and, for Carrara Marble, values from other labs (Dennis et al., 2011). $\Delta_{47}$ of standards are all within 1 to 2 standard errors of their accepted values (Table A1). $\Delta_{47}$ standard deviations of carbonate standards in this study range from 0.013 to $0.017 \%$. These values are similar to, though slightly elevated over that expected from counting statistics $(\sim 0.01 \%)$. Additionally, these standard 
deviations are similar to those published previously for carbonate standards measured at Caltech (0.013 to $0.03 \%$; Dennis et al., 2011) and elsewhere (0.01 to $0.038 \%$; Dennis et al., 2011). Standard deviations for $\delta^{18} \mathrm{O}$ were 0.07 to $0.10 \%$ and for $\delta^{13} \mathrm{C}$ were 0.02 to $0.05 \%$. These values are typical for measurements made at Caltech.

Phosphorite samples have similar, but slightly elevated (i.e., worse) experimental reproducibility as compared to the carbonate standards - apatites have $\delta^{18} \mathrm{O}$ external precisions that are 0.14 to $0.17 \%$ higher than our carbonate standards and 0.004 to $0.008 \%$ higher for $\Delta_{47}$ measurements (Tables A1 and A2). This decrease in external precision could be due to, for example, heterogeneities in the samples or a result of a poorer performance of the acid digestion reaction for large phosphate samples. Regardless, the additional imprecision does not impact any of our interpretations.

Two samples (ASP 6 and ASP 12) investigated gave high $\mathrm{CO}_{2}$ yields compared to other samples despite acid washing. Although there is nothing obviously exceptional with the isotopic data generated for these samples (they follow the same trends as other samples) they are not included in our discussion because it seems possible to us that they were contaminated by a carbonate-bearing phase other than apatite that was not removed with the acetic acid (e.g., dolomite).

All measured (including replicate) $\delta^{13} \mathrm{C}, \delta^{18} \mathrm{O}$, and $\Delta_{47}$ values for phosphorite samples and carbonate standards are given in Supplementary Tables 1 and 2.

\subsection{Sample cleaning experiments}

Cleaning experiments were performed to ensure calcite could be quantitatively removed without modifying a sample's $\delta^{18} \mathrm{O}_{\mathrm{CO} 3}, \delta^{13} \mathrm{C}_{\mathrm{CO} 3}$, and $\Delta_{47}$ values. A phosphorite sample from Florida, obtained from the Caltech mineralogical collection, was used for these experiments. This sample was reacted with either deionized water, buffered acetic acid $(0.1 \mathrm{M}, \mathrm{pH}=4.5)$, or triammonium citrate $(0.5 \mathrm{M}, \mathrm{pH}=0.5)$. Additionally, for some experiments, a spike of Carrara marble was added such that the spike was $5 \%$ by weight of the sample. These spiked samples were additionally reacted in either acetic acid or TAC for 4 hours, 24 hours, or 48 hours respectively. In no experiments were samples first pretreated with $\mathrm{H}_{2} \mathrm{O}_{2}$.

\subsection{Conversion of $\Delta_{47}$ values to temperature}

All $\Delta_{47}$ values (in the absolute reference frame) were converted into 'apparent equilibrium' temperatures or 'fictive' temperatures (Zhang, 1994), which we term here $\Delta_{47}$-based temperatures or $T_{\Delta 47}$, using $\Delta_{47}$ values. There currently exist multiple calibrations for conversion of $\Delta_{47}$ values in the absolute reference frame into apparent equilibrium temperatures (Dennis et al., 2011; Henkes et al., 2013; Zaarur et al., 2013; Eagle et al., 2013; Wacker et al., 2014; Defliese et al., 2015; Kluge et al., 2015).

$300\left(\% /{ }^{\circ} \mathrm{C}\right)$ by factors of up to 2 . The cause of these differences is not known. It is not 
obviously related to sample preparation differences (Wacker et al., 2014; Defliese et al., 302 2015). Furthermore, in the few cases where the same samples were measured in different

303 labs, the $\Delta_{47}$ values obtained were statistically indistinguishable (Dennis et al., 2011).

We have chosen to use a slightly modified version (see section A1 and equation A1) of the original temperature vs. $\Delta_{47}$ calibration of Ghosh et al. (2006) translated into the absolute reference by Dennis et al. (2011) for the following two reasons: (i) this calibration was generated in the Caltech laboratory where all measurements reported here were made, though at $25^{\circ} \mathrm{C}$ for acid digestions as opposed to $90^{\circ} \mathrm{C}$ as they are currently done. And (ii) apatite samples from bioapatite fossil material ranging in known formation temperatures from $24^{\circ} \mathrm{C}$ to $37^{\circ} \mathrm{C}$ yield $\Delta_{47}$-based temperatures using a $90^{\circ} \mathrm{C}$ acid digestion and the Ghosh et al. (2006) calibration that are within 1 standard error (s.e.) of the known formation temperatures in all cases (Eagle et al., 2010). We note that the use of the other calibrations does not change any first-order conclusions made here. Additionally all reported clumped-isotope-based temperatures are within the range of temperatures used in the calibration of Ghosh et al. (2006), 1 to $50^{\circ} \mathrm{C}$, except for one sample which is within 1 s.e. of $50^{\circ} \mathrm{C}(51 \pm 3,1$ s.e. $)$. Thus, the possible inaccuracies associated with extrapolating the Ghosh et al., calibration to temperatures outside its range of calibration are not factors here.

Finally, implicit in using any of the clumped-isotope calibrations discussed above, which are all based on carbonate minerals (e.g., calcite, aragonite, or dolomite), is that carbonate groups dissolved in apatites share an identical $\Delta_{47}$ vs. temperature relationship with the carbonate minerals used in the calibration. As discussed and demonstrated in Eagle et al. (2010) and Stolper and Eiler (2015), this appears, empirically, to be a robust assumption for samples with formation temperatures from $\sim 25$ to $\sim 700^{\circ} \mathrm{C}$. This assumption is further supported by theoretical calculations that indicate carbonate groups in apatite vs. in other carbonate groups share an indistinguishable $\Delta_{47}$ vs. temperature relationship (Eagle et al., 2010).

\section{Results of acid washing experiments}

A challenge with making clumped-isotope measurements on carbonate groups dissolved in apatite is that a large amount of sample is needed for each analysis: $\sim 100 \mathrm{mg}$ of apatite compared to $8 \mathrm{mg}$ of calcite. Thus, a critical concern for our analyses is the contamination of samples by small amounts (e.g., weight percent) of exogenous carbonate minerals. To deal with this, previous studies have used weak acids like acetic acid and triammonium citrate (TAC) to dissolve calcite and aragonite, but leave apatite isotopically undisturbed (Silverman et al., 1952; Kolodny and Kaplan, 1970; Shemesh et al., 1988; Koch et al., 1997; Eagle et al., 2010; Stolper and Eiler, 2015). Although these acids have been used to clean apatites for $\delta^{18} \mathrm{O}$ and $\delta^{13} \mathrm{C}$ measurements, their effects on $\Delta_{47}$ values are not fully constrained - Eagle et al. (2010) and Stolper and Eiler (2015) showed that acetic acid does not appear to change $\Delta_{47}$ values of carbonate groups in fossil material or igneous apatites. However, the samples used in the experiments of Eagle et al. (2010) and Stolper and Eiler (2015) were not known to contain contaminants. 
347 Consequently, how acid washes affect $\Delta_{47}$ values when contaminants are present is not

348 known. To address this, we measured the effects of acid washing on $\Delta_{47}$ values using 349 TAC, acetic acid, or deionized water on a phosphorite sample from the Caltech 350 mineralogical collection with and without additions (i.e., spikes) of calcite (see section 3512.4 above).

\subsection{Washing without calcite spikes}

We present the results of these acid-washing experiments in Figure 1 and Table 3. First, we discuss the results in samples that were not spiked with calcite. Interestingly and unexpectedly, washing samples in deionized water has an effect on both the measured $\delta^{18} \mathrm{O}$ and $\Delta_{47}$ values. Specifically, within the first 4 hours of washing in deionized water, samples plateau to constant (within error) $\delta^{18} \mathrm{O}_{\mathrm{CO} 3}, \delta^{13} \mathrm{C}_{\mathrm{CO} 3}$, and $\Delta_{47}$ values (Figure 1). We interpret this change then stabilization to indicate the dissolution and thus removal of a contaminant. We do not know what contaminant is being removed in the water, but we hypothesize it causes a mass-spectrometric interference at mass 46, raising the sample's $\delta^{18} \mathrm{O}_{\mathrm{CO} 3}$ value and thus lowering the $\Delta_{47}$ value (Figure 1). Water washing vs. acid washing in TAC or acetic acid appears to yield indistinguishable isotopic values (within analytical error) after 4 hours of treatment. This suggests that once this contaminant is dissolved, acid washing is no different from soaking samples in water. Additionally, this experiment shows the importance of rinsing all phosphorite (and perhaps other) samples before making isotopic measurements.

\subsection{Washing with calcite spikes}

The addition of aliquots of Carrara marble to the samples without subsequent acid washing causes a change in $\delta^{13} \mathrm{C}$ and $\Delta_{47}$ values as would be expected. The $\delta^{18} \mathrm{O}$ value of the marble-spiked samples is the same as the unwashed, unspiked samples and thus is not useful for monitoring the removal of the carbonate spike. Regardless, the measurements of $\delta^{13} \mathrm{C}$ and $\Delta_{47}$ demonstrate that acetic acid removes the calcite spike within 4 hours, while TAC removes it within 48 hours (Figure 1). Based on these experiments, we chose to use a 48-hour acetic-acid wash for all samples.

\section{Phosphorite Data}

4.1 Comparison of measurements to those in Shemesh et al. (1988) and first-order observations based on the isotopic compositions

Data for all phosphorite samples are given in Tables 1 and 2 , including $\Delta_{47}, \delta^{13} \mathrm{C}_{\mathrm{CO} 3}$, and $\delta^{18} \mathrm{O}_{\mathrm{CO} 3}$ values measured in this study and $\delta^{18} \mathrm{O}_{\mathrm{PO} 4}, \delta^{13} \mathrm{C}_{\mathrm{CO} 3}$ and $\delta^{18} \mathrm{O}_{\mathrm{CO} 3}$ values previously measured in Shemesh et al. (1988). We first compare our measurements of $\delta^{13} \mathrm{C}_{\mathrm{CO} 3}$ and $\delta^{18} \mathrm{O}_{\mathrm{CO} 3}$ values to those given in Shemesh et al. (1988) in Figure 2. The comparison of measurements of both $\delta^{13} \mathrm{C}_{\mathrm{CO} 3}$ and $\delta^{18} \mathrm{O}_{\mathrm{CO} 3}$ from the two studies defines trends that are statistically indistinguishable from 1:1 lines passing through the origin of the respective plots: The best-fit linear regression slope and intercept for the $\delta^{13} \mathrm{C}_{\mathrm{CO} 3}$ 
comparison are $1.05 \pm 0.06$ ( 1 standard deviation, $\sigma$ ) and $0.0 \pm 0.4(1 \sigma)$ respectively. For the $\delta^{18} \mathrm{O}_{\mathrm{CO} 3}$ comparison, the best-fit linear regression slope and intercept are $0.94 \pm 0.08$ $(1 \sigma)$ and $0.8 \pm 2.0(1 \sigma)$. Consequently, we conclude that there are no systematic offsets between the measurements from the two labs. We note, though, that there is scatter beyond the stated error for each point around the 1:1 line for both measurements (Figure 1). This scatter may be due to heterogeneities in the samples or perhaps due to different methodologies used - Shemesh et al. (1988) released $\mathrm{CO}_{2}$ from apatites using an acid digestion at $25^{\circ} \mathrm{C}$ in McCrea-style reactors (McCrea, 1950) while we used a common acid bath held at $90^{\circ} \mathrm{C}$ with continuous trapping of evolved $\mathrm{CO}_{2}$ at liquid nitrogen temperatures.

$\delta^{13} \mathrm{C}$ values of carbonate groups in the measured apatites tend to be lower as compared to typical values for Phanerozoic marine carbonates $\left(\delta^{13} \mathrm{C} \approx 2 \pm 4 \%\right.$; Lasaga, 1989), ranging in value from -0.5 to $-9.5 \%$. These ranges are similar to those observed in apatite-bound carbonate groups in other phosphorites (McArthur et al., 1980; Birch et al., 1983; Shemesh et al., 1983; McArthur et al., 1986; Shemesh et al., 1988; Kastner et al., 1990; Jarvis, 1992; Sadaqah et al., 2007; Baioumy et al., 2007). Low $\delta^{13} \mathrm{C}$ values in phosphorites are often attributed to incorporation carbonate groups generated in sedimentary pore waters by the respiration of organic matter that is typically lower in $\delta^{13} \mathrm{C}\left(\delta^{13} \mathrm{C} \approx-25 \%\right.$ ) than marine carbonates (e.g., McArthur et al., 1986).

$\delta^{18} \mathrm{O}_{\mathrm{PO} 4}$ values of the sample suite (taken from Shemesh et al., 1988) range from 15.8 to $23.4 \%$. For comparison, in modern (i.e., $\sim<100,000$ year old) phosphorites, $\delta^{18} \mathrm{O}_{\mathrm{PO} 4}$ values range from 21.7 to $24.8 \%$ (Shemesh et al., 1983; Shemesh et al., 1988). The $\delta^{18} \mathrm{O}_{\mathrm{CO} 3}$ values we measured for these samples range from 17.6 to $35 \%$ while modern phosphorites tend to range from 30.5 to $33.6 \%$ (Kolodny and Kaplan, 1970; Shemesh et al., 1983; Shemesh et al., 1988). Thus, many of the samples exhibit oxygen isotope values outside of the range observed in recent phosphorites, with most samples lower in both $\delta^{18} \mathrm{O}_{\mathrm{PO} 4}$ and $\delta^{18} \mathrm{O}_{\mathrm{CO} 3}$ than generally encountered today or the recent past.

$\Delta_{47}$ values in the absolute reference frame range from 0.613 to $0.724 \%$. These correspond to $\Delta_{47}$-based temperatures of 22 to $51^{\circ} \mathrm{C}$ - i.e., from plausible earth-surface temperatures to temperatures that presumably reflect either: $(i)$ kinetic isotope effects during precipitation (e.g., Ghosh et al., 2006; Affek et al., 2008; Daëron et al., 2011; Saenger et al., 2012) (ii) mixing between carbonate groups formed in or brought to isotopic equilibrium (and thus at homogenous phase equilibrium) but incorporated into the apatite over a range of temperatures during different diagenetic events; or (iii) intra-mineral, closed-system isotope-exchange reactions (Ghosh et al., 2006; Dennis and Schrag, 2010; Passey and Henkes, 2012; Henkes et al., 2014; Stolper and Eiler, 2015). We evaluate these possibilities in the next section (section 4.2).

Two correlations are present in the data: First, $\delta^{18} \mathrm{O}_{\mathrm{CO} 3}$ and $\delta^{18} \mathrm{O}_{\mathrm{PO} 4}$ values are linearly correlated with each other, with the best-fit line having a slope of $0.46 \pm 0.05(1 \sigma)$ (Figure 3a). This is similar to, but just statistically distinct at the $2 \sigma$ level, from the previously observed slope of 0.57 (Shemesh et al., 1988). This difference is possibly related to the additional samples examined by Shemesh et al. (1988) that were not 
439 measured here, including various Cenozoic samples with elevated $(>23 \%$ o $) \delta^{18} \mathrm{O}_{\mathrm{PO} 4}$ 440 values. Second, $1000 \times \ln \left(\alpha_{\mathrm{CO} 3-\mathrm{PO} 4}\right)$ values are linearly correlated with the measured 441 clumped-isotope temperatures, expressed as $1000 / \mathrm{T}$, where $\mathrm{T}$ is temperature in Kelvin 442 (Figure $3 b ; \alpha_{a-b}=\left[1000+\delta_{A}\right] /\left[1000+\delta_{B}\right]$ ), with a slope of $25.0 \pm 6.1(1 \sigma)$ and intercept 443 of $-74.2 \pm 25.1(1 \sigma)$. These correlations can be seen alternatively by plotting $\Delta_{47}$ vs.

$444 \delta^{18} \mathrm{O}_{\mathrm{CO} 3}$ and $\delta^{18} \mathrm{O}_{\mathrm{PO} 4}$ (Figure 4). As expected, linear correlations exist in these 445 composition spaces as well.

\subsection{Evaluation of intramineralic thermodynamic equilibrium}

\subsubsection{Can $\Delta_{47}$-based temperatures record mineral formation temperatures?}

A key question is how to interpret the $\Delta_{47}$-based temperatures of the samples. For example, are the measured temperatures mineral formation/recrystallization temperatures? This would require the carbonate groups to have been in homogenous phase equilibrium during mineral formation/recrystallization. This assumption was taken by Bradbury et al. (2015): They observed $\Delta_{47}$-based temperatures of $61^{\circ} \mathrm{C}$ in two samples and $66^{\circ} \mathrm{C}$ in another sample $\left( \pm 5^{\circ} \mathrm{C} 1\right.$ s.e. for all three) in apatites from phosphorites in the Monterey Formation. These temperatures are clearly too high to be the actual phosphorite formation temperatures. Consequently, Bradbury et al. (2015) interpreted the clumpedisotope temperatures as the temperatures at which the apatites recrystallized (or were otherwise diagenetically modified). This interpretation requires that any resetting of clumped-isotope temperatures via diagenesis occurred at a single temperature in a process that allowed all carbonate groups in the phosphorite to obtain a new internal isotopic equilibrium.

Thus, a critical question is whether phosphorite $\Delta_{47}$-based temperatures, before potential post-depositional modification, record mineral formation temperatures. Or, alternatively, are the $\Delta_{47}$ values controlled by kinetic isotope effects? If so, the measured temperatures would be unrelated (or related through processes other than the equilibrium relationship) to environmental formation temperatures. This is important to evaluate because formation in isotopic equilibrium would allow phosphorites to be used for paleotemperature reconstructions of formational and perhaps diagenetic environments. Evaluation of this requires samples with independently constrained formation temperatures. Problematically, independent constraints on mineral formation temperatures do not exist for the majority of samples given their geologically ancient age (multiple millions of years).

ASP 22, the likely youngest sample examined (1-5 million years old; Table 1), may provide some useful constraints. This sample, from off the coast of Namibia, is identified in Shemesh (1990) as a glauconized pelletal phosphorite. These glauconized pelletal phosphorites are hypothesized to have formed in evaporitic onshore estuary environments (Bremner and Rogers, 1990). Although the temperatures in these ancient estuaries are not known, modern sea-surface temperatures in the area are $\sim 18^{\circ} \mathrm{C}$ (Gammelsrød et al., 1998). This temperature is within $2 \sigma$ of the measured $\Delta_{47}$-based temperature of ASP-22, $48422^{\circ} \mathrm{C}( \pm 2,1$ s.e.) and thus could represent plausible mineral formation temperatures. 
485 Based on this result we suggest and proceed with the assumption that $\Delta_{47}$-based 486 temperatures of unmodified phosphorites can reflect mineral formation temperatures and 487 thus that there is no obvious presence of kinetic isotope effects affecting clumped-isotope 488 compositions during mineral formation. However, this remains a hypothesis and future 489 work should test this interpretation by examining modern phosphorite deposits with well490 constrained formation temperatures.

491

492

530 We compared these phosphate-water calibrations to two separate carbonate-water

\subsubsection{Do the $\delta^{18} \mathrm{O}_{\mathrm{PO} 4}$ and $\delta^{18} \mathrm{O}_{\mathrm{CO} 3}$ values and clumped isotope temperatures reflect the formation/recrystallization temperatures of the phosphorites?}

Next, we examined whether the trends in Figure 3 are consistent with formation of apatites in oxygen-isotope equilibrium between $\mathrm{PO}_{4}{ }^{3-}$ and $\mathrm{CO}_{3}{ }^{2-}$ groups and internal isotopic equilibrium between carbonate groups for clumped isotopologues. This was done using experimentally derived oxygen-isotope fractionation factors (the $\alpha$ above) between carbonate and water and between phosphate and water. Multiple phosphate-water fractionation factors exist and need to be considered (Kolodny et al., 1983; Karhu and Epstein, 1986; Shemesh et al., 1988; Lécuyer et al., 1996; Pucéat et al., 2010; Lécuyer et al., 2013). As all but one of the samples measured here was made on $\mathrm{BiPO}_{4}$ (Kolodny et al., 1983), we only considered calibrations generated using the $\mathrm{BiPO}_{4}$ method.

After examining the relevant calibrations, we chose two equilibrium phosphate-water oxygen-isotope fractionation calibrations for this test: the low temperature calibration $\left(<25^{\circ} \mathrm{C}\right)$ of Kolodny et al. (1983) and the high temperature $\left(<510^{\circ} \mathrm{C}\right)$ calibration of Shemesh et al. (1988). We did not include the calibration of Longinelli and Nuti (1973) as it is identical within error to that of Kolodny et al. (1983). Additionally, we did not include the calibration of Karhu and Epstein (1986) because the high-temperature datum from this study is included in the Shemesh et al. (1988) calibration. We note that some caution should be taken when using the Shemesh et al. (1988) calibration for two reasons: First, one of the high-temperature $\left(>350^{\circ} \mathrm{C}\right)$ data points was taken from Karhu and Epstein (1986) and this sample has an estimated $\left(350^{\circ} \mathrm{C}\right)$ as opposed to known formation temperature. Second, the other high-temperature $\left(510^{\circ} \mathrm{C}\right)$ data point used to calibrate the phosphate-water oxygen-isotope fractionation factor vs. temperature from the Shemesh et al. (1988) study implies the presence of a so-called 'crossover' in the calibration (Stern et al., 1968). Specifically, all low-temperature (e.g., from the surface of the earth) phosphates formed in isotopic equilibrium have $\delta^{18} \mathrm{O}$ values that are greater than the $\delta^{18} \mathrm{O}$ values of the fluid from which they precipitated. However, the highest temperature $\left(510^{\circ} \mathrm{C}\right)$, experimentally derived apatite has a $\delta^{18} \mathrm{O}$ value that is lower than a fluid would have if it were isotopically equilibrated with the mineral. The presence of this crossover makes use of a linear $1 / \mathrm{T}^{2}$ form for the temperature dependence of the fractionation factor, which is the form used in the Shemesh et al. (1988) calibration, potentially incorrect. This is because the trend may not be linear between the high temperature and low temperature points used for the calibration (Stern et al., 1968). Regardless, we consider this calibration as it is found in the literature and includes calibration points at elevated $\left(>25^{\circ} \mathrm{C}\right)$ temperatures. 
531 fractionation factors for four total comparisons. The first carbonate-water calibration used 532 is the Kim and O'Neil (1997) calibration for calcite. Although carbonate groups in apatite are distinct from those in calcite, calcite-based fractionation factors have been used in the past to interpret the meaning of carbonate oxygen isotopes in phosphates (e.g., Shemesh et al., 1983; Shemesh et al., 1988; McArthur and Herczeg, 1990). The second calibration is from Lécuyer et al. (2010) and is for carbonate groups substituted into hydroxyapatite in equilibrium with water.

We compared our results to the four different lines that can be produced from the calibrations described above in Figure 5. In Figure 5a, for the calculated relationships between $\delta^{18} \mathrm{O}_{\mathrm{PO} 4}$ and $\delta^{18} \mathrm{O}_{\mathrm{CO} 3}$ in apatite, we assumed mineral formation in waters with a $\delta^{18} \mathrm{O}=0 \%$, which is the approximate average value of modern seawater. Using the estimated average isotopic composition of the ocean without continental ice sheets (1.2\% ; Miller et al., 1987) does not change any conclusions. The isotopic composition of the water controls the vertical position of the lines in figure 5a. For example, changing the $\delta^{18} \mathrm{O}$ of the water in equilibrium with the minerals moves the position of the lines along a 1:1 line. Importantly, the $\delta^{18} \mathrm{O}$ of water has no effect on the slopes of the lines. In Figure $5 \mathrm{~b}, 1000 \mathrm{x} \ln \left(\alpha_{\mathrm{CO} 3-\mathrm{PO} 4}\right)$ vs. $1000 / \mathrm{T}$ for the models is compared to the measured $\Delta_{47}$-based temperatures. Unlike in Figure 5a, this space (Figure 5b) is independent of the chosen isotopic composition of the water.

In figure 5a, the two lines defined by the combination of the Kim and O'Neil (1997) carbonate calibration with the phosphate calibrations of Kolodny et al. (1983) and the line defined by the combination of Lécuyer et al. (2010) with Shemesh et al. (1988) produce slopes that are steeper than the slope defined by the data trend. This was also observed by Shemesh et al. (1988) when attempting a similar exercise. If any of these lines are the correct combination of fractionation factors, it would suggest that, although some of the points may lie on or near lines that define isotopic equilibrium, many are significantly offset. Such offsets would indicate the presence of disequilibrium processes that have disturbed some samples away from oxygen-isotope equilibrium between the phosphate and carbonate groups. This was the conclusion of Shemesh et al. (1988).

Interestingly, the line in Figure 5a, which is based on combination of the Lécuyer et al. (2010) and Shemesh et al. (1988) calibrations, has a slope that is generally consistent with the trend of the data. Closer inspection, however, demonstrates that this line's goodness of fit is fortuitous. Specifically, as discussed above, one sample examined here, ASP 22, has a well-constrained formational and burial history. This sample was dredged from the sea-floor (and thus experienced limited burial diagenesis) in waters with a temperature of $\sim 12^{\circ} \mathrm{C}$ (Shemesh et al., 1983) and likely formed at higher temperatures (see discussion in section 4.2.1). However, the calculated temperature based on the $\delta^{18} \mathrm{O}_{\mathrm{PO} 4}$ and $\delta^{18} \mathrm{O}_{\mathrm{CO} 3}$ values and the Lécuyer et al. (2010) vs. Shemesh et al. (1988) fractionation factors is $-8^{\circ} \mathrm{C} \pm 3(1 \sigma)$. This temperature is $2 \sigma$ below the modern freezing point of seawater, $-2^{\circ} \mathrm{C}$, and significantly below the current environmental temperatures. This demonstrates that despite the visual goodness of fit of the Lécuyer et al. (2010) vs. Shemesh et al. (1988) line in Figure 5a, the temperatures derived using this line do not yield reasonable mineral formation temperatures for the sample with the best constrained 
formation and diagenetic history.

Based on this, we suggest, as concluded previously by Shemesh et al. (1988), that the $\delta^{18} \mathrm{O}$ values from the full suite of data examined are not consistent with the carbonate and phosphate groups preserving mutual oxygen-isotope equilibrium at formation in the whole sample set for any of the examined $\delta^{18} \mathrm{O}$ vs. temperature calibrations for carbonate and phosphate groups. This does not indicate that all samples are isotopically modified, just that there are many samples that are isotopically disturbed away from $\delta^{18} \mathrm{O}$ equilibrium. This inference is further supported by comparison of the measured $\Delta_{47}$-based temperatures vs. $1000 \times \ln \left(\alpha_{\mathrm{CO} 3-\mathrm{PO} 4}\right)$ trend observed in figure $3 \mathrm{~b}$ to the trends predicted based temperatures are, in many cases, not the temperatures that would have been predicted based on the bulk oxygen isotopic compositions $\left(\delta^{18} \mathrm{O}_{\mathrm{CO} 3}\right.$ and $\left.\delta^{18} \mathrm{O}_{\mathrm{PO} 4}\right)$ of the apatites and the various published calibrations. This is a particularly informative comparison because the positions of the lines in figure $5 \mathrm{~b}$, unlike in $5 \mathrm{a}$, are independent of the composition of the water in which the apatite formed. Thus the lack of agreement between the $\Delta_{47}$-based temperatures and the predicted temperatures from the difference in $\delta^{18} \mathrm{O}$ between the carbonate and phosphate groups provides supporting and independent evidence that many apatites contain phosphate and carbonate groups that are out of mutual isotopic equilibrium.

As discussed above, the apparent mismatch between the observed $\delta^{18} \mathrm{O}_{\mathrm{CO} 3}$ and $\delta^{18} \mathrm{O}_{\mathrm{PO} 4}$ values vs. those expected for isotopic equilibrium was suggested by Shemesh et al. (1988) to be the result of diagenesis. Specifically, Shemesh et al. (1988) hypothesized that during burial, both the carbonate groups and phosphate groups partially exchanged oxygen with sedimentary fluids at either elevated temperatures or in waters with lower $\delta^{18} \mathrm{O}$ values. Additionally, they attributed the general shallowness of the slope for the data trend observed in figures $3 \mathrm{a}$ and $5 \mathrm{a}$ compared to that expected for mutual isotopic equilibrium between phosphate and carbonate groups to be the result of different rates of oxygen-isotope exchange between water and phosphate groups vs. water and carbonate groups. Specifically, they suggested that the carbonate groups exchanged oxygen atoms more quickly with water than the phosphate groups did.

The clumped-isotope data support this diagenetic model because the temperatures measured correlate with the $\delta^{18} \mathrm{O}$ values of both the $\mathrm{CO}_{3}$ and $\mathrm{PO}_{4}$ groups (Figure 4) Specifically, the higher clumped-isotope temperatures correspond to lower the $\delta^{18} \mathrm{O}$ values for both the phosphate and carbonate groups. This correlation, as well as that between $\delta^{18} \mathrm{O}_{\mathrm{PO} 4}$ and $\delta^{18} \mathrm{O}_{\mathrm{CO} 3}$ (Figures 3a and 5a) suggests the presence of a process capable of lowering the $\delta^{18} \mathrm{O}$ values of both the carbonate and phosphate groups in concert while at the same time raising the measured $\Delta_{47}$-based temperatures. Such correlations can be explained through increasing degrees of diagenesis in a waterbuffered system at elevated temperatures. This would cause the measured clumped isotope temperatures to increase while, at the same time, the $\delta^{18} \mathrm{O}$ values to decrease either due to the smaller difference in $\delta^{18} \mathrm{O}$ at isotopic equilibrium between water and carbonate and phosphate minerals at elevated temperatures (Urey, 1947; McCrea, 1950; 
Epstein et al., 1953; O'Neil et al., 1969; Longinelli and Nuti, 1973; Kolodny et al., 1983; Kim and O'Neil, 1997; Lécuyer et al., 2010) or due to lower $\delta^{18} \mathrm{O}$ values of diagenetic fluids compared to the fluids present during mineral precipitation. In the next section, we take this hypothesis and develop a quantitative model to explicitly test its plausibility.

Before exploring this model, we note that there is an alternative explanation for the presence of elevated $\Delta_{47}$-based temperatures $\left(>\approx 30^{\circ} \mathrm{C}\right)$ relative to what would be expected for earth-surface conditions in many of the samples: the $\Delta_{47}$-based temperatures could have been partially reset through closed-system isotope-exchange reactions mediated by solid-state short-range diffusion within the mineral lattice (Ghosh et al., 2006; Dennis and Schrag, 2010; Passey and Henkes, 2012; Henkes et al., 2014; Stolper and Eiler, 2015). This is plausible as, at least in the few high-temperature apatites measured from (igneous) carbonatites, the blocking temperature for the $\Delta_{47}$-based thermometer (i.e., the approximate temperature above which solid-state atomic mobility can reset the apparent temperature) may be as low as $\sim 70$ to $80^{\circ} \mathrm{C}$ in carbonate groups in apatite (Stolper and Eiler, 2015). However, this explanation does not provide an obvious mechanism for the co-variation between the measured clumped-isotope temperatures and the $\delta^{18} \mathrm{O}_{\mathrm{CO} 3}$ and $\delta^{18} \mathrm{O}_{\mathrm{PO} 4}$ values (Figures 3, 4 and 5) - closed-system isotope exchange will not cause the $\delta^{18} \mathrm{O}$ values of the phosphate groups (which buffer the isotopic composition of the apatite) to change. Consequently, as diagenesis can explain the covariation between $\delta^{18} \mathrm{O}$ values of phosphate and the $\Delta_{47}$-based temperatures while closedsystem isotope-exchange reactions cannot, we do not consider closed-system isotopeexchange processes further.

\section{A diagenetic model for the isotopic composition of phosphorite apatite}

\subsection{The model}

The divergence between the observed $\delta^{18} \mathrm{O}_{\mathrm{CO} 3}$ and $\delta^{18} \mathrm{O}_{\mathrm{PO} 4}$ values and $\Delta_{47}$-based temperatures from the relationships expected for mineral formation in isotopic equilibrium with water (Figure 5) as well as their correlations with each other (Figures 3 and 4) suggests that a non-equilibrium process is modifying both the bulk and clumpedisotopic compositions for some samples away from isotopic equilibrium. Furthermore, the correlations between $\delta^{18} \mathrm{O}_{\mathrm{CO} 3}$ and $\delta^{18} \mathrm{O}_{\mathrm{PO} 4}$ values (Figure 3a) and the $\Delta_{47}$-based temperatures with both $\delta^{18} \mathrm{O}_{\mathrm{CO} 3}$ and $\delta^{18} \mathrm{O}_{\mathrm{PO} 4}$ (Figure 5) requires that whatever nonequilibrium processes is at work, it acts on both the carbonate and phosphate groups (and is generally regular in its behavior, despite our having examined samples from many different geological times and locations). A process that can accomplish this is the partial dissolution and reprecipitation of a sample over a range of temperatures and/or fluid isotopic compositions during burial in sediments. In such a case, a sample would consist of a mixture of diagenetic and original components. Although all mineral components, both diagenetic and original, may have formed in isotopic equilibrium with sedimentary pore waters, the calculated temperature based on difference in $\delta^{18} \mathrm{O}_{\mathrm{PO} 4}$ and $\delta^{18} \mathrm{O}_{\mathrm{CO} 3}$ as well as the $\Delta_{47}$-based temperature as measured on that mixture would not be interpretable as physically meaningful formation/re-equilibration temperatures. Instead this temperature would represent a mixture of signals originating from the original 
precipitation event and later diagenesis. Although such measurements could lead to an interpretable signal, the process altering the original isotopic composition must be recognized and understood first. In this section we examine the consequences of such diagenetic reactions on the measured isotopic parameters.

A key aspect of the diagenesis of apatites to consider is that during dissolution and reprecipitation reactions, $\mathrm{CO}_{3}{ }^{2-}$ and $\mathrm{PO}_{4}{ }^{3-}$ groups may exchange oxygen with waters at different rates. As discussed above, such a difference was originally suggested by Shemesh et al. (1988) as a key control on the correlation between $\delta^{18} \mathrm{O}_{\mathrm{CO} 3}$ and $\delta^{18} \mathrm{O}_{\mathrm{PO}}$ seen in Figure 3a. Furthermore, such differential reaction rates have been shown experimentally: In the absence of organisms, phosphate groups exchange oxygen isotopes with water more slowly than carbonate groups do. In contrast, in experiments that include organisms, phosphate groups in apatite exchange oxygen isotopes more rapidly with water than carbonate groups do (Zazzo et al., 2004; see below).

We explore the consequences of diagenetic reactions that promote exchange of oxygenisotopes between phosphate and carbonate groups with water quantitatively using a model based on the kinetic framework described in Criss et al. (1987) and Gregory et al. (1989). This framework is designed to describe the kinetics of isotope-exchange reactions between multiple phases/species with water (or any other phase) and allows different phases to react at different rates. Note, however, that the model assumes reacting species follow equilibrium fractionations; i.e., it is a kinetic model but does not involve kinetic isotope effects. We use this framework to explore the trajectories that diagenesis creates during alteration of $\delta^{18} \mathrm{O}_{\mathrm{CO} 3}, \delta^{18} \mathrm{O}_{\mathrm{PO} 4}$ and $\Delta_{47}$ values when carbonate and phosphate groups react at different rates in the composition spaces outlined in Figures 3 and 5.

Using the kinetic rate laws derived in Criss et al. (1987) and Gregory et al. (1989) for bulk oxygen-isotope exchange reactions in a water buffered system, it can be shown that:

$$
\mathrm{F}_{\mathrm{PO} 4}=\left(\mathrm{F}_{\mathrm{CO} 3}\right)^{\mathrm{k}_{\mathrm{PO} 4} / \mathrm{k}_{\mathrm{CO} 3}} \text {. }
$$

In equation (1), $F=\left({ }^{18} R_{\text {measured }}{ }^{18} R_{\text {equilibrium }}\right) /\left({ }^{18} R_{\text {initial }}{ }^{18} R_{\text {equilibrium }}\right)$, where the equilibrium value represents the final value after a sample has fully recrystallized and is in isotopic equilibrium with the fluid. ' $\mathrm{k}$ ' is the rate constant for oxygen-isotope exchange between carbonate $\left(\mathrm{k}_{\mathrm{CO} 3}\right)$ or phosphate $\left(\mathrm{k}_{\mathrm{PO} 4}\right)$ with water. $\mathrm{F}$ can take on values from 1 to 0 where 1 indicates no reaction has taken place while 0 is complete reaction. This model was previously used by Zazzo et al. (2004) to quantify different isotope-exchange rates between carbonate and phosphate groups in apatite with water on ground-up (100-700 micron) fossil teeth and bone bioapatite (hydroxyapatite) with and without microorganisms. They found $\mathrm{k}_{\mathrm{PO} 4} / \mathrm{k}_{\mathrm{CO} 3}$ ratios of 0.1 for abiotic experiments and 2 to 15 for biotic reactions.

In order to extend this model to clumped-isotope exchange reactions in carbonates (which to our knowledge has not been done) we make the following additional assumptions:

(i) We assume that the kinetics of the clumped-isotope composition of the apatites can be described and modeled using $\Delta_{47}$ values. This assumption holds if there is a constant 
713 offset between the carbonate's clumped isotopologue composition (dominated [97\%] by 714 the abundance of the mass 63 isotopologue, ${ }^{13} \mathrm{C}^{16} \mathrm{O}_{2}{ }^{18} \mathrm{O}$ ) and its $\Delta_{47}$ value - this has been 715 observed to be the case experimentally (Ghosh et al., 2006; Guo et al., 2009). We note, though, that theoretical calculations indicate that $\Delta_{47}$ values could be non-linear functions of a sample's carbonate clumped-isotope composition (Guo et al., 2009), but, as of yet, this has not been observed empirically.

(ii) We assume that changes in abundances of mass 47 isotopologues $\left({ }^{13} \mathrm{C}^{16} \mathrm{O}^{18} \mathrm{O}\right.$, $\left.{ }^{12} \mathrm{C}^{17} \mathrm{O}^{18} \mathrm{O},{ }^{13} \mathrm{C}^{17} \mathrm{O}_{2}\right)$ vs. mass 44 isotopologue $\left({ }^{12} \mathrm{C}^{16} \mathrm{O}_{2}\right)$ of the $\mathrm{CO}_{2}$ derived from the carbonate groups obey the following kinetic form, which is also based on the kinetic derivations described in Criss et al. (1987) and Gregory et al. (1989):

$$
\frac{{ }^{47} R_{\text {measured }}-{ }^{47} R_{\text {equilibrium }}}{{ }^{47} R_{\text {initial }}-{ }^{47} R_{\text {equilibrium }}}=\mathrm{e}^{-k_{47} t}
$$

where, in this equation, the 'measured' value has been modified from the initial value after time ' $t$ '. Consequently,

$$
\mathrm{F}_{47}=\left(\mathrm{F}_{\mathrm{CO} 3}\right)^{\mathrm{k}_{77} / \mathrm{k}_{\mathrm{CO} 3}}
$$

where $F_{47}=\left({ }^{47} R_{\text {measured }}{ }^{47} R_{\text {equilibrium }}\right) /\left({ }^{47} R_{\text {initial }}{ }^{47} R_{\text {equilibrium }}\right)$ and $k_{47}$ is the rate constant. Equations similar to (2) have been derived for or applied to other clumped-isotope studies involving kinetic processes (Passey and Henkes, 2012; Affek, 2013; Clog et al., 2015). Because $\Delta_{47}$ values depend not only on ${ }^{47} \mathrm{R}$ values, but also on bulk isotopic composition, the full equation describing the change in $\Delta_{47}$ with time is:

$$
\Delta_{47}=\left(\frac{\left({ }^{47} \mathrm{R}_{\text {initial }}-{ }^{47} \mathrm{R}_{\text {equilibrium }}\right) \times\left(\mathrm{F}_{\mathrm{CO}_{3}}\right)^{\mathrm{k}_{47} / \mathrm{K}_{\mathrm{CO}}}+{ }^{47} \mathrm{R}_{\text {equilibrium }}}{2^{13} \mathrm{R} \times{ }^{18} \mathrm{R}+{ }^{13} \mathrm{R} \times\left({ }^{17} \mathrm{R}\right){ }^{2}+2{ }^{27} \mathrm{R} \times{ }^{18} \mathrm{R}}-1\right) \times 1000
$$

where the denominator is equivalent to ${ }^{47} \mathrm{R} *$ (Affek and Eiler, 2006). For all calculations we hold the $\delta^{13} \mathrm{C}$ value of the carbonates constant. We note that large differences in both the $\delta^{13} \mathrm{C}$ and $\delta^{18} \mathrm{O}$ (e.g., $10 \%$ ) of the starting and ending carbonate compositions will cause non-linear clumped-isotope mixing effects (e.g., Eiler and Schauble, 2004) that are large enough to be worth considering. For example take two carbonate minerals with identical $\Delta_{47}$ values, and, let one have $\delta^{18} \mathrm{O}$ and $\delta^{13} \mathrm{C}$ values $10 \%$ lower than the other. An equal mixture of the two will have a $\Delta_{47}$ value $\sim 0.025 \%$ higher than either of the end members. We avoid this complexity here by fixing $\delta^{13} \mathrm{C}$, which greatly diminishes this non-linearity, introducing deviations of $<0.001 \%$ from linear mixing of $\Delta_{47}$.

In order to calculate the oxygen isotopic composition of apatite phosphate and carbonate groups in isotopic equilibrium with water we use the fractionation factors of Kolodny et al. (1983) and Lécuyer et al. (2010). We do not use the Shemesh et al. (1988) calibration due to its dependence on high temperature $\left(>300{ }^{\circ} \mathrm{C}\right)$ points that are either poorly constrained or imply a crossover (which may be present, but in any case prohibits linear interpolations; see above). We use the Lécuyer et al. (2010) over the Kim and O'Neil (1997) calibration because the Lécuyer et al. (2010) calibration was experimentally generated with carbonate groups in apatites (though hydroxyapatites) as opposed to calcites. We acknowledge, though, that these calibrations may, themselves, be inaccurate, but consider them the best currently available for this model. To aid in understanding this 
754 model, we provide a schematic figure (Figure 6) that illustrates the different paths that 755 diagenesis takes in the composition spaces of Figures 3 and 5 depending on the

\subsection{Application of the model to conditions relevant for phosphorite formation and diagenesis}

We applied this model to phosphorite formation and modification in the context of bulk and clumped isotopic compositions for two different diagenetic paths. For both, we assumed that all samples initially formed in oxygen and clumped-isotope equilibrium at $25^{\circ} \mathrm{C}$ in water with $\delta^{18} \mathrm{O}$ value of $0 \%$ (the approximate average value of seawater today). This is clearly an oversimplification, but we consider it sufficient for the exploration of the model as a valid framework to describe the data. The first pathway has diagenesis occurring at $80^{\circ} \mathrm{C}$ (i.e., hotter than initial formation temperatures) in pore waters with $\delta^{18} \mathrm{O}=-4 \%$. Such environments commonly occur $\sim 1.5$ to $3 \mathrm{~km}$ oceanic sediments sitting on oceanic crust with geotherms ranging from 20 to $40{ }^{\circ} \mathrm{C} / \mathrm{km}$ and decreases in porewater $\delta^{18} \mathrm{O}$ of $\sim 2-15 \% / \mathrm{km}$ (Lawrence and Gieskes, 1981). Alternatively, such low $\delta^{18} \mathrm{O}$ pore waters could also result from infiltration of meteoric waters (Epstein and Mayeda, 1953; Craig, 1961; Dansgaard, 1964; Bowen, 2010) into sediments. The second pathway is modeled to occur at $10^{\circ} \mathrm{C}$ (i.e. colder than the initial formation temperature) in waters that are isotopically identical to the formation waters $\left(\delta^{18} \mathrm{O}=0 \%\right.$ ). Such a scenario could be imagined to occur if sinking bones and teeth (e.g., from fish) or continentally derived apatites were deposited and underwent reaction in cold, deep waters on a continental slope. It is worth noting that these paths are not mutually exclusive - materials may first undergo diagenetic reactions during deposition in cold water followed by diagenesis at elevated temperatures.

These models require a choice for both the ratio of $\mathrm{k}_{47} / \mathrm{k}_{\mathrm{CO} 3}$ and $\mathrm{k}_{\mathrm{PO} 4} / \mathrm{k}_{\mathrm{CO} 3}$. We chose $\mathrm{k}_{47} / \mathrm{k}_{\mathrm{CO} 3}$ to be equal to 1 , implying no difference in ${ }^{18} \mathrm{O} /{ }^{16} \mathrm{O}$ exchange rate on ${ }^{13} \mathrm{C}$ abundance. This assumption is consistent with experimental results constraining rates of exchange between $\mathrm{CO}_{2}$ and liquid water (Affek, 2013; Clog et al., 2015). We use a value of 1 because it is the expected value if carbonate ions in solution are always in both oxygen-isotope equilibrium with water and clumped-isotope equilibrium. In this case, the rate of isotopic exchange between mineral and water should be governed only by the net rate of dissolution and reprecipitation reactions. We chose the $\mathrm{k}_{\mathrm{PO} 4} / \mathrm{k}_{\mathrm{CO} 3}$ value that simultaneously best fit the data (using a least-squares minimization) in both figures $3 \mathrm{a}$ and $b$, and along both diagenetic pathways (Figure 7). This yielded a value of 0.53 . However, we note that visually acceptable fits range from 0.3 to 0.6 . This ratio could and should vary across environments depending on, for example, inorganic dissolution and reprecipitation rates, mineral composition, availability of organisms to enzymatically catalyze oxygen exchange in $\mathrm{PO}_{4}^{3-}$ groups, and temperature. For simplicity and in the absence of better constraints, we have chosen a constant value for the model. We note that this value is distinct from those found by Zazzo et al. (2004) for experimental dissolution and reprecipitation of fossil hydroxyapatite in the presence of microorganisms $\left(\mathrm{k}_{\mathrm{PO} 4} / \mathrm{k}_{\mathrm{CO} 3}\right.$ from 2 to 15$)$ as discussed above and is more similar to the ratio of 0.1 obtained for the inorganic experiments. This may indicate that inorganic reactions are significant 
during phosphate oxygen isotope exchange processes during diagenesis.

\subsection{Comparison of the model framework to the data}

We provide the calculated model trajectories for this diagenetic framework in Figure 7. A few key insights can be taken away from this exercise. First, as seen in Figure 7, this diagenetic model is able to capture the overall structure of the measured data for both the bulk isotopes and clumped isotopes. This indicates the bulk and clumped-isotope compositions of phosphorites can be explained, to first order, by formation in isotopic equilibrium with water and then, for altered samples, diagenesis at either elevated temperatures in waters with lower $\delta^{18} \mathrm{O}$ values or diagenesis at lower temperatures in waters of similar isotopic composition as formation. The overall success of the model at describing the trends in the data indicates that the combination of $\delta^{18} \mathrm{O}_{\mathrm{PO} 4}, \delta^{18} \mathrm{O}_{\mathrm{CO} 3}$, and temperatures based on $\Delta_{47}$ values provide a more complete understanding of both the formation and subsequent modification of these samples.

Despite this success, the model is clearly only suitable, as applied, here, for first-order conclusions. For example, samples scatter about the trends and, especially for the low temperature paths, do not yield precisely the same amount of diagenesis in both Figures $5 \mathrm{a}$ and $\mathrm{b}$. Some of this disagreement is likely related to our assumption that all phosphorites form at identical temperatures and in fluids with identical $\delta^{18} \mathrm{O}$ values and then undergo diagenesis along one of two paths with fixed temperatures, relative rate constants, and $\delta^{18} \mathrm{O}_{\mathrm{H} 2 \mathrm{O}}$ values. This is clearly a gross oversimplification. For example, apatites derived from terrestrial organisms could have formed in waters with different $\delta^{18} \mathrm{O}$ values than marine systems (Luz et al., 1984a). Finally, it is not clear that the chosen fractionation factors for oxygen isotope equilibrium between carbonate and phosphate groups in apatite is correct. Presumably the scatter in the data about the trajectories of the model is related, at least in part, to mismatches between the data and the simplicity of our model assumptions. Nevertheless, the critical point is that the main trend in the data is consistent with a simple, plausible model of diagenesis.

Second, the comparison of the diagenetic model to the data provides a potential insight into the creation and diagenesis of phosphorites (and perhaps other carbonate bearing materials) with $\delta^{18} \mathrm{O}$ values that are several per mil lower than is commonly observed in modern day marine phosphates. Such low $\delta^{18} \mathrm{O}$ values are often assumed to be the result of diagenesis in meteorically derived fluids or in marine pore waters at elevated temperatures (e.g., Degens and Epstein, 1962; Killingley, 1983; Land, 1995). However, there are alternative explanations for low $\delta^{18} \mathrm{O}$ values in ancient samples that instead invoke a change in the $\delta^{18} \mathrm{O}$ value of the ocean to lower values (e.g., Veizer et al., 1997; Veizer et al., 1999; Kasting et al., 2006; Jaffrés et al., 2007) or precipitation of samples in the past at elevated temperatures (e.g., Knauth and Epstein, 1976; Karhu and Epstein, 1986). The association we observe between higher clumped-isotope temperatures and er $\delta^{18} \mathrm{O}$ values (Figures 3 and 5), combined with the fit of the model to the data, is 843 most consistent with the interpretation that diagenesis plays a key role in lowering the $844 \quad \delta^{18} \mathrm{O}$ value of many phosphorites. 
846 Third, the success of the model supports the view that $\mathrm{PO}_{4}{ }^{3-}$ groups are more resistant to exchange in natural materials than $\mathrm{CO}_{3}{ }^{2-}$ groups (Shemesh et al., 1983; Shemesh et al., 1988; Longinelli et al., 2003). However, it is also clear from this data that in the case of phosphorites, apatites can be open to significant amounts of oxygen-isotope exchange with water for both carbonate and phosphate groups. Indeed, the arrays observed in Figure 7 could potentially be used as a test of digenesis in other samples - if samples fall on disequilibrium arrays in both the $\delta^{18} \mathrm{O}_{\mathrm{CO} 3}-\delta^{18} \mathrm{O}_{\mathrm{PO} 4}$ space (Figure $7 \mathrm{a}$ ) and $\Delta_{47}$-based temperature space (Figure $7 \mathrm{~b}$ ) the presence of diagenesis could be identified unambiguously.

\section{Do apatites ever fully re-equilibrate their oxygen isotopes during diagenesis?}

An interesting aspect of the model when fit to the data is that for the high-temperature diagenesis pathway, no samples appear to return to the lines that define oxygen and internal isotopic equilibrium in Figures $5 \mathrm{a}$ and b. Instead, all samples observed remain below $\sim 50 \%$ re-equilibration (Figure 7 ). The precise percent of re-equilibration is controlled by the assumed temperature of the diagenetic reactions. Thus our finding of $50 \%$ is qualitative. What is important is that no samples with elevated clumped-isotope temperatures or low $\delta^{18} \mathrm{O}_{\mathrm{CO} 3}$ or $\delta^{18} \mathrm{O}_{\mathrm{PO} 4}$ values have returned to the values expected for an isotopically equilibrated mineral.

A question then is do apatites, once isotopically modified, ever return to isotopic equilibrium both internally for clumped isotopes and for oxygen-isotope equilibrium between phosphate and carbonate groups? To answer this, we can compare the phosphorite apatite samples to apatites from igneous carbonatite intrusions that formed at elevated temperatures. These igneous apatites crystallized at temperatures above $\sim 600{ }^{\circ} \mathrm{C}$ or so, but preserve lower clumped-isotope temperatures due to internal isotope-exchange reactions that take place during cooling (Stolper and Eiler, 2015). Thus, their clumpedisotope compositions are altered after mineral crystallization, but in a different process from the phosphorites. In contrast to the phosphorites, these igneous samples fall on or near the expected range of equilibrium lines (within the $\pm 1 \sigma$ error bounds) for their clumped-isotope temperature (Figure $7 \mathrm{~b}$; we do not include them in $7 \mathrm{a}$ as this space depends on the isotopic composition of formation waters which is not relevant for igneous apatites). This analysis indicates that during cooling, when these exchange reactions ceased, the clumped-isotope and oxygen-isotope compositions of the $\mathrm{PO}_{4}{ }^{3-}$ and $\mathrm{CO}_{3}{ }^{2-}$ groups 'closed' at the same temperature. Thus apatites that undergo reactions that alter their carbonate and phosphate oxygen-isotope and clumped-isotope compositions after formation can end up in or near the positions expected for isotopic equilibrium in

884 Figures $3 \mathrm{~b}, 4 \mathrm{~b}$ and $7 \mathrm{~b}$. This finding may have implications for our understanding of the 885 chemical controls of the clumped-isotope apparent blocking temperature in apatite - i.e., 886

889 Based on this, we must now ask why it is that the diagenetically modified phosphorites, 890 even those hundreds of millions of years old, have not fully re-equilibrated their oxygen 
isotopes between carbonate and phosphate groups? From the data and model, it appears

892 that apatites readily undergo 10 's of percent re-equilibration towards diagenetic 893 conditions, but struggle to go to completion. The answer to this may lie with the fact that 894 the model of Criss et al. (1987) and Gregory et al. (1989) implicitly assumes that all 895 oxygen bearing groups are equally capable of undergoing isotope-exchange reactions at 896 all times. However in nature this is not necessarily the case. For example, water may be 897 incapable of penetrating and exchanging oxygen with all atoms in an apatite grain due to 898 a lack of pores/channels to the interior of the original mineral. We suggest that this occurs 899 due to 'armoring' of original grains with impermeable diagenetic rims as schematically 900 outlined and shown with natural samples in Figure 8. Indeed the presence of apatite cores 901 surrounded and armored with apatite rims is commonly observed in phosphorite deposits 902 (figure 8; Cook, 1972; Braithwaite, 1980; Glenn and Arthur, 1988).

903

The importance of such geometric restrictions on the rates of dissolution and reprecipitation has recently been modeled quantitatively and shown to be of generic importance to minerals undergoing diagenesis (Reeves and Rothman, 2013). If correct, such a model indicates that the temperatures derived from clumped-isotope analyses of mixtures of relict and newly grown minerals, even those heavily modified by diagenesis, do not represent any particular diagenetic recrystallization temperature or event. The temperatures instead represent a mixed signal originating from both the original depositional temperature and the temperature range over which diagenesis occurred. If this phenomenon occurs elsewhere, e.g., in calcites or dolomites, it may have implications for the meaning of clumped-isotope based reconstructions of diagenetic recrystallization temperatures and fluid compositions. This model could be tested by using an ion probe to measure the difference in $\delta^{18} \mathrm{O}$ between phosphate cores vs. rims. This is because the model presented above predicts significant (5-10\%o) differences in $\delta^{18} \mathrm{O}$ values between the relict, original core and the rim that formed during diagenesis. Specifically, if the model is correct, it would indicate that clumped-isotope temperatures of bulk, diagenetically altered phosphorites (and perhaps other carbonate-bearing phases) do not represent a discrete temperature of diagenesis, as has been assumed, but instead represent the integrated history of formation and alteration, incorporating signals from both original precipitation and later diagenetic modification at a variety of temperatures.

\section{Summary and Conclusions}

The measurements of oxygen isotopes of carbonate groups and phosphate groups in apatites from phosphorites combined with clumped-isotope temperatures for the carbonate groups yield linear relationships between $\delta^{18} \mathrm{O}_{\mathrm{CO} 3}$ and $\delta^{18} \mathrm{O}_{\mathrm{PO} 4}$ as well as $1000 \ln \left(\alpha_{\mathrm{CO} 3-\mathrm{PO} 4}\right)$ and $1 / \mathrm{T}$ where $\mathrm{T}$ is the derived clumped-isotope temperature of the carbonate groups. These relationships cannot be fully reconciled with any current equilibrium-based interpretation of the bulk isotopes or clumped-isotope temperatures. Instead, the clumped-isotope temperatures of phosphorites demonstrate and reinforce that isotopic equilibrium captured during mineral formation is overprinted by diagenetic reactions in many samples. We interpret and model these results in a quantitative framework that incorporates isotope-exchange reactions during diagenesis. In this model, 936 the originally precipitated samples exchange oxygen isotopes with water during 
937 diagenesis. Using this model, we showed the relationships observed between $\delta^{18} \mathrm{O}_{\mathrm{CO} 3}$, $938 \delta^{18} \mathrm{O}_{\mathrm{PO} 4}$, and the clumped-isotope temperatures can be understood as the consequence of 939 varying amounts of oxygen-isotope exchange for both phosphate and carbonate groups with fluids. We required that the isotope exchange reactions occur at different temperatures and fluid isotopic compositions as compared to the original formation, with most altered samples best fit by diagenesis in a higher temperature setting with lower $\delta^{18} \mathrm{O}$ fluids. Furthermore this kinetic framework required more rapid isotope exchange reactions between carbonate and water vs. phosphate and water. This supports the hypothesis that apatites in phosphorites undergo isotopic exchange reactions with water in both the carbonate and phosphate groups during burial and diagenesis, but that the phosphate groups are more resilient to modification than the carbonate groups. This model indicates that for phosphorites that have been isotopically modified, both elevated temperatures and waters with $\delta^{18} \mathrm{O}$ values lower than seawater are involved. Such information provides insight into the timing and location of diagenesis suggesting that diagenetic isotope-exchange reactions occur during burial at kilometer depths in fluids that are only slightly modified from seawater.

An additional insight from the model is that none of the sedimentary phosphorites, even those hundreds of millions of years old, re-establish isotopic equilibrium during diagenesis; i.e., the carbonate and phosphate groups never develop an oxygen isotope fractionation consistent with the diagenetic temperature implied by the clumped-isotope compositions of carbonate groups. This lack of full isotopic re-equilibration is interpreted as a consequence of the fact that phosphorite diagenesis leads to armoring of relict primary apatite with rims of secondary diagenetic apatite, preventing further diagenesis of the relict cores. In instances such as this, the clumped-isotope temperatures of bulk diagenetically modified phases reflect mixing between apatite formed at the original mineral formation temperature and secondary apatite formed at the range of diagenetic reaction temperatures. This insight may have implications for the interpretation clumpedisotope temperatures of diagenetically modified phases in other settings and minerals.

Acknowledgements: We wish to thank Yehoshua Kolodny and Boaz Luz of the Hebrew University in Jerusalem for providing the samples and helpful discussions. We additionally wish to thank Aldo Shemesh of the Weizmann Institute for helpful discussions. We thank two anonymous reviewers, Cedric John, and our associate editor, Hagit Affek, for helpful comments. DAS would like to thank his PhD thesis committee of Jess Adkins, Woodward Fischer, John Grotzinger, and Alex Sessions (along with John Eiler) for sage advice and guidance. DAS acknowledges the NSF GRFP for support. JME acknowledges the support of the NSF-EAR program for instrumentation. 


\section{Tables}

Table 1: Age, location, and bulk isotopic compositions of all samples measured.

\begin{tabular}{|c|c|c|c|c|c|c|c|c|c|}
\hline Sample & Location & $\begin{array}{l}\text { Age } \\
\text { (ma) }\end{array}$ & $\begin{array}{l}\delta^{13} \mathrm{C}(\% o) \\
{\text { (this study })^{\mathrm{a}}}\end{array}$ & $\pm^{\mathrm{b}}$ & $\begin{array}{l}\delta^{18} \mathrm{O}_{\mathrm{CO} 3}(\% o) \\
\text { (this study })^{\mathrm{c}}\end{array}$ & $\pm^{\mathrm{b}}$ & $\begin{array}{l}\delta^{13} \mathrm{C}_{\mathrm{CO} 3}(\% \circ) \\
(\text { Shemesh et al., 1988) }\end{array}$ & $\begin{array}{l}\delta^{18} \mathrm{O}_{\mathrm{CO} 3}(\% o) \\
(\text { Shemesh et al., 1988) }\end{array}$ & $\begin{array}{l}\delta^{18} \mathrm{O}_{\mathrm{PO} 4}(\%) \\
(\text { Shemesh et al., 1988) }\end{array}$ \\
\hline ASP 3 & Phosphoria, $\mathrm{USA}^{\mathrm{g}}$ & 265 & -3.30 & 0.02 & 17.59 & 0.07 & -3.5 & 16.8 & 15.8 \\
\hline ASP 4 & Monterey, Mexico & 30 & -6.79 & 0.01 & 25.89 & 0.08 & -6.8 & 24 & 19.1 \\
\hline ASP 9 & Rassaif, Israel ${ }^{\mathrm{g}}$ & 75 & -8.69 & 0.01 & 24.43 & 0.04 & -9.9 & 21.8 & 19 \\
\hline ASP 15 & G. Rechavam, Israel ${ }^{\mathrm{g}}$ & 75 & -7.27 & 0.04 & 23.54 & 0.14 & -6.8 & 22.8 & 17.3 \\
\hline ASP 22 & Off-Shore, Namibia ${ }^{\text {h }}$ & 1 to $5^{\mathrm{e}}$ & -1.90 & 0.03 & 35.05 & 0.21 & -1.9 & 32.7 & 23.4 \\
\hline ASP 28 & Sechura, Peru ${ }^{\mathrm{g}}$ & 14 & -5.22 & 0.01 & 31.36 & 0.05 & -5.1 & 30.4 & 22.3 \\
\hline ASP 46 & Quseir, Egypt ${ }^{\mathrm{g}}$ & 75 & -5.70 & 0.02 & 21.13 & 0.18 & -6.3 & 21.3 & 17.7 \\
\hline ASP 49 & Monterey, Baja & 30 & -6.88 & 0.00 & 25.69 & 0.05 & -6.9 & 25.4 & 19 \\
\hline ASP 78 & Blake Plateau ${ }^{\mathrm{h}}$ & 26 & -0.52 & 0.02 & 31.69 & 0.11 & -1.1 & 31.1 & 23 \\
\hline ASP 84 & Oron, Israel ${ }^{\mathrm{g}}$ & 75 & -9.52 & 0.08 & 25.50 & 0.14 & -10.5 & 26.5 & 20.2 \\
\hline ASP 105 & Central Florida, USA $^{\mathrm{g}}$ & 3.4 & -5.45 & 0.01 & 29.03 & 0.03 & -5.7 & 28.2 & 20.4 \\
\hline NBS $120 \mathrm{C}$ & & & -6.29 & 0.01 & 29.40 & 0.03 & - & - & 20.3 \\
\hline $\operatorname{ASP} 6^{\mathrm{f}}$ & Arad, Israel ${ }^{\mathrm{g}}$ & 75 & -8.34 & 0.01 & 24.59 & 0.11 & -8.3 & 22.5 & 18.6 \\
\hline $\operatorname{ASP} 12^{\mathrm{f}}$ & Bir Zafra, Egypt ${ }^{\mathrm{g}}$ & 75 & -6.90 & 0.01 & 21.56 & 0.24 & -5.1 & 21.5 & 16.2 \\
\hline
\end{tabular}

$978{ }^{a}$ referenced to the VPDB scale

$979{ }^{\mathrm{b}} 1$ standard error

980 'referenced to VSMOW

981 measured on $\mathrm{BiPO}_{4}$ except for NBS 120c (measured as $\mathrm{Ag}_{3} \mathrm{PO}_{4}$ ), which has been converted to the $\mathrm{BiPO}_{4}$ reference frame. See section 2.1 .

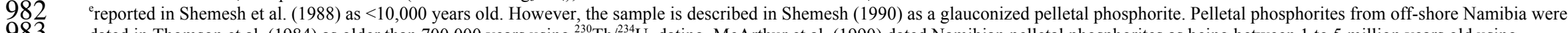

983 dated in Thomson et al. (1984) as older than 700,000 years using ${ }^{230} \mathrm{Th} /{ }^{234} \mathrm{U}$, dating. McArthur et al. (1990) dated Namibian pelletal phosphorites as being between 1 to 5 million years old using

984 strontium isotopes. Such ages are consistent with the facies model of Bremner and Rogers (1990) and are adopted here.

985 produced larger quantities of $\mathrm{CO}_{2}$ than other experiments and thus are excluded from all discussion in case of contamination by exogenous carbonate phases not removed during acid washing.

987 outcrop sample

$987{ }^{\text {h }}$ dredged from the seafloor 
988 Table 2: $\Delta_{47}$ values and calculated clumped-isotope-based temperatures for all samples 989 measured.

\begin{tabular}{llllllll} 
Sample & $n^{\mathrm{a}}$ & $\Delta_{47 . \text { ARF }}(\%)^{\mathrm{b}}$ & $\pm^{\mathrm{c}}$ & $\Delta_{48}$ & $\pm^{\mathrm{c}}$ & $\mathrm{T}_{\text {ARF }}\left({ }^{\circ} \mathrm{C}\right)^{\mathrm{e}}$ & $\pm^{\mathrm{c}}$ \\
\hline ASP 3 & 4 & 0.613 & 0.010 & 0.0 & 0.2 & 47 & 2 \\
ASP 4 & 6 & 0.685 & 0.009 & 0.5 & 0.2 & 30 & 2 \\
ASP 9 & 4 & 0.659 & 0.007 & 0.3 & 0.0 & 36 & 2 \\
ASP 15 & 5 & 0.654 & 0.012 & 0.6 & 0.5 & 37 & 3 \\
ASP 22 & 7 & 0.724 & 0.011 & 0.2 & 0.1 & 22 & 2 \\
ASP 28 & 4 & 0.678 & 0.007 & 0.5 & 0.1 & 32 & 2 \\
ASP 46 & 5 & 0.601 & 0.011 & 0.3 & 0.2 & 51 & 3 \\
ASP 49 & 6 & 0.665 & 0.011 & 0.3 & 0.1 & 35 & 2 \\
ASP 78 & 4 & 0.696 & 0.009 & 0.5 & 0.1 & 28 & 2 \\
ASP 84 & 4 & 0.658 & 0.010 & 0.5 & 0.2 & 36 & 2 \\
ASP 105 & 5 & 0.663 & 0.008 & 0.5 & 0.1 & 35 & 2 \\
NBS 120C & 10 & 0.720 & 0.005 & 0.1 & 0.2 & 23 & 1 \\
ASP 6 & 4 & 0.628 & 0.019 & 0.3 & 0.1 & 45 & 5 \\
ASP 12 & 2 & 0.677 & 0.009 & 0.5 & 0.3 & 31 & 2
\end{tabular}

990 anumber of samples measured

991 biven in the absolute reference frame (ARF) of Dennis et al. (2011).

$992{ }^{c} 1$ standard error

993 produced larger quantities of $\mathrm{CO}_{2}$ than other experiments and thus excluded from all discussion in case of contamination by

994 exogenous carbonate phases not removed during acid washing.

995 eapparent clumped-isotope-based temperature calculated using equation (A1) 
996 Table 3: Acid washing experiments

\begin{tabular}{|c|c|c|c|c|}
\hline Sample & $\delta^{13} \mathrm{C}(\%)^{\mathrm{a}}$ & $\delta^{18} \mathrm{O}(\%)^{\mathrm{b}}$ & $\left.\Delta_{47, \operatorname{ARF}}(\%)\right)^{\mathrm{c}}$ & $\pm^{\mathrm{d}}$ \\
\hline unwashed apatite starting material & -5.39 & 29.55 & 0.537 & 0.007 \\
\hline 4 hours deionized (DI) water & -5.37 & 29.27 & 0.616 & 0.012 \\
\hline 24 hours DI water & -5.38 & 29.24 & 0.630 & 0.011 \\
\hline 48 hours DI water & -5.42 & 29.27 & 0.667 & 0.019 \\
\hline 4 hours acetic acid & -5.36 & 29.24 & 0.646 & 0.012 \\
\hline 24 hours acetic acid & -5.43 & 29.27 & 0.624 & 0.013 \\
\hline 48 hours acetic acid & -5.42 & 29.35 & 0.633 & 0.010 \\
\hline 4 hours triammonium citrate (TAC) & -5.42 & 29.29 & 0.651 & 0.008 \\
\hline 24 hours TAC & -5.39 & 29.16 & 0.636 & 0.008 \\
\hline 48 hours TAC & -5.42 & 29.33 & 0.646 & 0.013 \\
\hline+ calcite $^{\mathrm{e}}$ with unwashed apatite starting material & -2.42 & 29.30 & 0.500 & 0.010 \\
\hline + calcite 4 hours acetic acid & -5.40 & 29.35 & 0.627 & 0.021 \\
\hline + calcite 24 hours acetic acid & -5.20 & 29.36 & 0.633 & 0.006 \\
\hline + calcite 48 hours acetic & -5.33 & 29.10 & 0.646 & 0.019 \\
\hline+ calcite 4 hours TAC & -4.43 & 29.30 & 0.624 & 0.009 \\
\hline + calcite 24 hours TAC & -5.00 & 29.37 & 0.638 & 0.017 \\
\hline + calcite 48 hours TAC & -5.38 & 29.24 & 0.666 & 0.013 \\
\hline \multicolumn{5}{|l|}{${ }^{\text {a }}$ referenced to the VPDB scale } \\
\hline \multicolumn{5}{|l|}{${ }^{\mathrm{b}}$ referenced to VSMOW } \\
\hline \multirow{2}{*}{\multicolumn{5}{|c|}{ 'given in the absolute reference frame (ARF) of Dennis et al. (2011) }} \\
\hline \multicolumn{2}{|c|}{${ }^{\mathrm{d}} 1$ standard error } & & & \\
\hline edenotes addition of calcite material to the experiment. & & & & \\
\hline
\end{tabular}

997 areferenced to the VPDB sca

998 breferenced to VSMOW

$999{ }^{c}$ given in the absolute reference frame (ARF) of Dennis et al. (2011)

$1000 \quad{ }^{\mathrm{d}} 1$ standard error

1001 edenotes addition of calcite material to the experiment.

1002 


\section{Figures}

1004

1005

1006

1007

1008

1009

1010

1011

1012

1013

1014

1015

1016

1017

1018

1019

1020

1021

1022

1023

1024

1025

1026

1027

1028

1029

1030

1031

1032

1033

1034

1035

1036

1037

1038

1039

1040

1041

1042

1043

1044

1045

1046

1047

1048

1049

1050

1051

1052

1053

1054

1055

1056

Figure 1. Apatite acid-cleaning experiments. TAC indicates triammonium citrate. '+ calcite' denotes addition of a Carrara marble spike to the experiment such that the spike was $5 \%$ by weight of the sample. A) Effect of different acid washes on $\delta^{13} \mathrm{C}$ values of $\mathrm{CO}_{3}{ }^{2-}$ groups liberated from a phosphorite standard. All samples converge to the same value, within error, by 48 hours. Error bars of the measurement are smaller than the symbols. B) Effect of different acid washes on $\delta^{18} \mathrm{O}$ values of $\mathrm{CO}_{3}{ }^{2-}$ groups liberated from a phosphorite standard. All samples converge to the same value, within error, by 48 hours. Given error bar is the typical \pm 1 standard deviation of the measurement. See A for legend. C) Effect of different acid washes on $\Delta_{47}$ values of $\mathrm{CO}_{3}{ }^{2-}$ groups liberated from a phosphorite standard. All samples converge to the same value, within error, by 48 hours. Given error bar is the typical \pm 1 standard deviation of the measurement. See A for legend.

Figure 2. Comparison of bulk isotopic measurements of $\mathrm{CO}_{3}{ }^{2-}$ groups in phosphorites from this study compared to those measured by Shemesh et al. (1988). Plotted lines are 1:1 lines that pass through the origin. A) Comparison of $\delta^{13} \mathrm{C}_{\mathrm{CO} 3}$ measurements. B) Comparison of $\delta^{18} \mathrm{O}_{\mathrm{CO} 3}$ measurements. Error bars are smaller than the symbols.

Figure 3. A) Relationship between $\delta^{18} \mathrm{O}_{\mathrm{PO} 4}$ values given in Shemesh et al. (1988) vs. $\delta^{18} \mathrm{O}_{\mathrm{CO} 3}$ values measured in this study. B) Relationship between $1000 \times \ln \left(\alpha_{\text {CO3-PO4 }}\right)$ vs. $1000 / T$ where $T$, in Kelvin, is the derived clumped-isotope-based temperature. $\alpha_{\mathrm{CO} 3-\mathrm{PO} 4}$ values are calculated as $\left(1000+\delta^{18} \mathrm{O}_{\mathrm{CO} 3}\right) /(1000+$ $\left.\delta^{18} \mathrm{O}_{\mathrm{PO}}\right)$. Error bars of data are \pm 1 standard error. Gray area outlines the $95 \%$ confidence interval of the linear, least-squares regression given by the dotted black lines.

Figure 4. Comparison of $\delta^{18} \mathrm{O}_{\mathrm{CO} 3}$ vs. the clumped-isotope $\left(\Delta_{47}\right.$-based) temperature and of $\delta^{18} \mathrm{O}_{\mathrm{PO} 4}$ vs. the clumped-isotope-based temperature. Both show linear correlations. Best fit lines are given as dotted lines with $95 \%$ confidence intervals as the shaded regions. We note that this is simply a different way of looking at the data presented in Figure 3.

Figure 5. A) Comparison of various theoretical lines for equilibrium between oxygen isotopes of $\mathrm{PO}_{4}{ }^{3-}$ and $\mathrm{CO}_{3}{ }^{2-}$ vs. the measured data. For the theoretical calculations, samples are assumed to have equilibrated with waters with a $\delta^{18} \mathrm{O}$ value equal to $0 \%$ : see text for details. B) Comparison of theoretical lines for $1000 \mathrm{x}$ $\ln \left(\alpha_{\mathrm{CO} 3-\mathrm{PO} 4}\right)$ vs. $1000 / \mathrm{T}$ where $\mathrm{T}$, in Kelvin, is the derived clumped-isotope temperature vs. the measured values. $\alpha_{\mathrm{CO} 3-\mathrm{PO} 4}$ values are calculated as $\left(1000+\delta^{18} \mathrm{O}_{\mathrm{CO} 3}\right) /\left(1000+\delta^{18} \mathrm{O}_{\mathrm{PO} 4}\right)$. Theoretical lines for carbonatewater fractionation factors for $\delta^{18} \mathrm{O}_{\mathrm{CO} 3}$ values are given in Kim and O'Neil (1997) and Lécuyer et al. (2010). Theoretical lines for $\mathrm{PO}_{4}$-water fractionation factors for $\delta^{18} \mathrm{O}_{\mathrm{PO} 4}$ values are given in Kolodny et al. (1983) and Shemesh et al. (1988). Error bars of data are \pm 1 standard error.

Figure 6. Schematic figure showing the diagenetic paths that oxygen-isotope exchange of phosphate and carbonate groups in apatite with water take in the spaces outlined in figures 3 and 5 . The legend is given in A. Dotted lines represent lines of isotopic equilibrium between carbonate and phosphate groups and clumped-isotope equilibrium. Solid lines are the diagenetic paths. In red is the high-temperature diagenetic path and in purple the low-temperature diagenetic path. The black circle represents the starting composition and the red and purple circles the ending composition for the high- and low-temperature paths respectively. In $\mathrm{A}$ and $\mathrm{B}$, phosphate and carbonate groups exchange oxygen isotopes with water at an equal rate. In $\mathrm{C}$ and $\mathrm{D}$, carbonate groups exchange oxygen isotopes with water more quickly than phosphate groups do. In $\mathrm{E}$ and $\mathrm{F}$, phosphate exchange oxygen isotopes more quickly with water than carbonate groups do. In all cases $\mathrm{k}_{47} / \mathrm{k}_{\mathrm{CO} 3}=1$ and $\delta^{13} \mathrm{C}_{\mathrm{CO} 3}$ is held constant.

Figure 7. Comparison of data to modeled trajectories during diagenesis. The model is described and developed in the text (section 5). All samples are assumed to have precipitated in isotopic equilibrium at $25^{\circ} \mathrm{C}$ in waters with a $\delta^{18} \mathrm{O}$ value of $0 \%$. Diagenesis at higher temperatures is assumed to occur at $80^{\circ} \mathrm{C}$ in waters with a $\delta^{18} \mathrm{O}$ value of $-4 \%$. Diagenesis at cooler temperatures is assumed to occur at $10^{\circ} \mathrm{C}$ in waters with a $\delta^{18} \mathrm{O}$ value of $0 \%$. The amount of diagenesis relative to the final value is given by the percentages 
with gradations of $25 \%$. The best-fit value for $\mathrm{k}_{\mathrm{PO} 4} / \mathrm{k}_{\mathrm{CO} 3}$ was found to be 0.53 (see text). A) Comparison of bulk $\delta^{18} \mathrm{O}_{\mathrm{CO} 3}$ and $\delta^{18} \mathrm{O}_{\mathrm{PO} 4}$ values vs. the model. B) Comparison of $1000 \times \ln \left(\alpha_{\mathrm{CO} 3-\mathrm{PO} 4}\right)$ vs. $1000 / \mathrm{T}$ where $\mathrm{T}$, in Kelvin, is the derived clumped-isotope-based temperature vs. the model. Carbonatite $\delta^{18} \mathrm{O}_{\mathrm{CO} 3}$ and clumped-isotope-based temperatures come from Stolper and Eiler (2015) for the Siilinjarvi and Oka apatites. The $\delta^{18} \mathrm{O}_{\mathrm{PO} 4}$ value for Siilinjarvi apatites was taken to be $4.9 \%$ using data from Tichomirowa et al. (2006). The $\delta^{18} \mathrm{O}_{\mathrm{PO} 4}$ value for Oka apatites was taken to be 5.6\%o using data from Conway and Taylor $\mathrm{Jr}$ (1969). $1 \sigma$ error ranges given for the model in the lighter colored, thinner lines were derived using the errors estimates given for the published $\mathrm{PO}_{4}-\mathrm{H}_{2} \mathrm{O}$ oxygen-isotope fractionation factor given in Lécuyer et al. (2010) and propagating that error through the model. Error bars are smaller than the data points.

Figure 8. Cartoon representation of the diagenesis of an apatite grain in comparison to grains from a phosphorite deposit. A) Starting collection of apatite minerals. B) Dissolution and reprecipitation of these minerals armors an inner, original core with an outer rim of diagenetic apatite. This outer rim would prevent further diagenesis of the inner core. C) Photomicrograph of phosphorite apatites from the Peru

1072 rimming the core (as marked). The photomicrograph was modified from Figure $6 \mathrm{~b}$ of Glenn and Arthur 1073 (1988). Reprinted with permission from Elsevier. 


\section{Appendix}

1076 A1. A recalculation of the dependence of $\Delta_{47}$ in the absolute reference frame on temperature taking into account the acid digestion correction used in this study

We modified the translation of the Ghosh et al. (2006) calibration to absolute reference frame as given in Dennis et al. (2011) to take into account new results on the value of the acid digestion fractionation factor between $90^{\circ} \mathrm{C}$ and $25^{\circ} \mathrm{C}$ acid baths in the absolute reference frame. Specifically, Henkes et al. (2013) demonstrated that the difference between samples prepared using $90^{\circ} \mathrm{C}$ and $25^{\circ} \mathrm{C}$ acid baths is, on average, $0.092 \%$ $( \pm 0.007,1$ s.e. $)$ in the absolute reference frame, and thus higher than the acid digestion factor $\left(0.081 \%\right.$ ) used in Dennis et al. (2011) to convert all measurements to a $25^{\circ} \mathrm{C}$ reference frame. We note that there have been recent suggestions for other values for this acid-digestion fractionation factor in the absolute reference frame including $0.066 \%$ for aragonite and $0.075 \%$ for calcite (Wacker et al., 2013) and $0.082 \%$ for calcite, aragonite, and dolomite (Defliese et al., 2015). Use of these different fractionation factors would change temperatures by up to $\sim 6^{\circ} \mathrm{C}$ at the temperature interval of interest to this study (20 to $50^{\circ} \mathrm{C}$ ). We chose to use the Henkes et al. (2013) calibration as the $\mathrm{CO}_{2}$ extraction line used in that studied was modeled after that used at Caltech. When this value $(0.092 \%)$ is used to place the NBS 19 standard measured in both the Ghosh et al. (2006) and Dennis et al. (2011) studies into the absolute reference frame, the value becomes $0.400 \%$ as opposed to 0.392\%o, as calculated in Dennis et al. (2011). Repeating the calculations performed in Dennis et al. (2011) to convert the $\Delta_{47}$ values of Ghosh et al. (2006) into the absolute reference, but using this new value for NBS 19 for the correction results in the following equation describing the dependence of $\Delta_{47}$ on temperature:

$$
\Delta_{47}=0.636 \times \frac{10^{6}}{\mathrm{~T}^{2}}-0.006
$$
1102 - differences between using the equation provided in Dennis et al. (2011) and equation 1103 (A1) result in differences in temperature of less than $0.2^{\circ} \mathrm{C}$ between the calibrations from 11041 to $50^{\circ} \mathrm{C}$, the range of temperatures used in the calibration. 
1105 Table A1: $\Delta_{47}$ accuracy and precision of standards and phosphorite samples.

1106
1107
1108
1109
1110
1111
1112
1113
1114
1115
1116

\begin{tabular}{lccccc} 
& $n^{\mathrm{a}}$ & $\left.\Delta_{47 . \text { ARF.this studv }}(\%)\right)^{\mathrm{b}}$ & $\pm^{\mathrm{c}}$ & $\Delta_{47 . \text { Caltech }}(\% 0)^{\mathrm{b}, \mathrm{d}}$ & $\Delta_{47 . \text { Dennis et al. (2011) }}(\% 0)^{\mathrm{b}, \mathrm{e}}$ \\
\hline Carrara Marble & 36 & 0.399 & 0.017 & 0.401 & 0.403 \\
TV01 & 31 & 0.721 & 0.013 & 0.724 & - \\
$\begin{array}{l}\text { Average } \\
\text { Phosphorites }^{\mathrm{f}}\end{array}$ & 69 & - & 0.021 & - & -
\end{tabular}

anumber of samples measured

biven in the absolute reference frame (ARF) of Dennis et al. (2011)

${ }^{c} 1$ standard deviation

${ }^{\mathrm{d}}$ Average, long-term value at Caltech

${ }^{\mathrm{e}}$ This value (in the absolute reference frame) is derived from Dennis et al. (2011) by taking the average value for the reported Carrara in-house marbles and increasing the Harvard, Johns Hopkins, and Caltech values by $0.011 \%$ to account for the use of a $90^{\circ} \mathrm{C}$ clumped isotope acid digestion fractionation of $0.092 \%$ used in this study instead of $0.081 \%$ as was used in that study.

fonly the standard deviation for the precision of all phosphorite measurements is given. This was done by taking the difference of each sample's $\Delta_{47}$ from the average value of the replicates for all samples and then taking the standard deviation of those differences for all data. No average is given as all samples are used for this analysis. 
1117 Table A2: $\delta^{13} \mathrm{C}$ and $\delta^{18} \mathrm{O}$ accuracy and precision of standards and phosphorite samples.

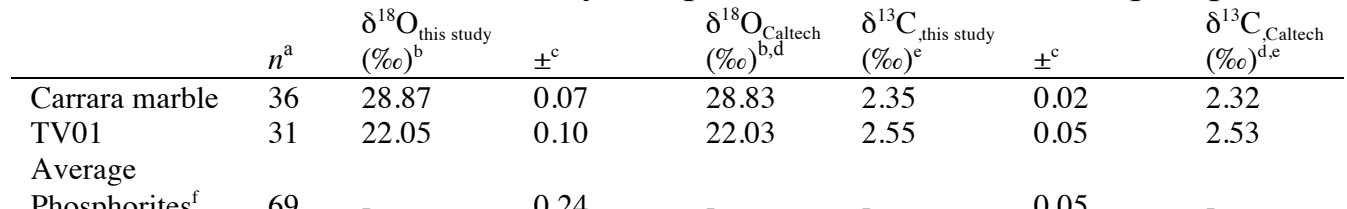

$\begin{array}{llllll}\text { Phosphorites }^{\mathrm{f}} & 69 & - & 0.24 & - & \end{array}$

1118 anumber of samples measured

${ }^{\mathrm{b}}$ referenced to VSMOW

${ }^{\mathrm{c}} 1$ standard deviation

${ }^{\mathrm{d}}$ Average, long-term value at Caltech

'referenced to the VPDB scale

${ }^{\mathrm{f}}$ only the standard deviation for the precision of all phosphorite measurements is given. This was done by taking the difference of each sample's $\delta$ from the average value of the replicates for all samples and then taking the standard deviation of those differences for all data. No average is given as all samples are used for this analysis. 
1126

1127

1128

1129

1130

1131

1132

1133

1134

1135

1136

1137

1138

1139

1140

1141

1142

1143

1144

1145

1146

1147

1148

1149

1150

1151

1152

1153

1154

1155

1156

1157

1158

1159

1160

1161

1162

1163

1164

1165

1166

1167

1168

1169

1170

1171

\section{References}

Affek, H.P., 2013. Clumped isotopic equilibrium and the rate of isotope exchange between $\mathrm{CO}_{2}$ and water. American Journal of Science 313, 309-325.

Affek, H.P., Bar-Matthews, M., Ayalon, A., Matthews, A., Eiler, J.M., 2008. Glacial/interglacial temperature variations in Soreq cave speleothems as recorded by 'clumped isotope'thermometry. Geochimica et Cosmochimica Acta 72, 5351-5360.

Affek, H.P., Eiler, J.M., 2006. Abundance of mass $47 \mathrm{CO}_{2}$ in urban air, car exhaust, and human breath. Geochimica et Cosmochimica Acta 70, 1-12.

Ayliffe, L., Chivas, A., Leakey, M., 1994. The retention of primary oxygen isotope compositions of fossil elephant skeletal phosphate. Geochimica et Cosmochimica Acta 58, 5291-5298.

Ayliffe, L.K., Herbert Veeh, H., Chivas, A.R., 1992. Oxygen isotopes of phosphate and the origin of island apatite deposits. Earth and Planetary Science Letters 108, 119129.

Baioumy, H., Tada, R., Gharaie, M., 2007. Geochemistry of Late Cretaceous phosphorites in Egypt: Implication for their genesis and diagenesis. Journal of African Earth Sciences 49, 12-28.

Birch, G., Thomson, J., McArthur, J., Burnett, W., 1983. Pleistocene phosphorites off the west coast of South Africa. Nature 302, 601-603.

Blake, R.E., O'Neil, J., Garcia, G., 1997. Oxygen isotope systematics of biologically mediated reactions of phosphate: I. Microbial degradation of organophosphorus compounds. Geochimica et Cosmochimica Acta 61, 4411-4422.

Bowen, G.J., 2010. Isoscapes: Spatial pattern in isotopic biogeochemistry. Annual Review of Earth and Planetary Sciences 38, 161-187.

Bradbury, H.J., Vandeginste, V., John, C.M., 2015. Diagenesis of phosphatic hardgrounds in the Monterey Formation: A perspective from bulk and clumped isotope geochemistry. Geological Society of America Bulletin, B31160. 31161.

Braithwaite, C.J., 1980. The petrology of oolitic phosphorites from Esprit (Aldabra), western Indian Ocean. Philosophical Transactions of the Royal Society of London. Series B, Biological Sciences, 511-540.

Bremner, J., Rogers, J., 1990. Phosphorite deposits on the Namibian continental shelf. Phosphate deposits of the world 3, 143-152.

Came, R.E., Eiler, J.M., Veizer, J., Azmy, K., Brand, U., Weidman, C.R., 2007. Coupling of surface temperatures and atmospheric $\mathrm{CO}_{2}$ concentrations during the Palaeozoic era. Nature 449, 198-201.

Clog, M., Stolper, D., Eiler, J.M., 2015. Kinetics of $\mathrm{CO}_{2(\mathrm{~g})}-\mathrm{H}_{2} \mathrm{O}_{(\mathrm{l})}$ isotopic exchange, including mass 47 isotopologues. Chemical Geology 395, 1-10.

Conway, C.M., Taylor Jr, H.P., 1969. $\mathrm{O}^{18} / \mathrm{O}^{16}$ and $\mathrm{C}^{13} / \mathrm{C}^{12}$ ratios of coexisting minerals in the Oka and Magnet Cove carbonatite bodies. The Journal of Geology, 618-626.

Cook, P.J., 1972. Petrology and geochemistry of the phosphate deposits of northwest Queensland, Australia. Economic Geology 67, 1193-1213.

Craig, H., 1961. Isotopic variations in meteoric waters. Science 133, 1702-1703.

Criss, R., Gregory, R., Taylor Jr, H., 1987. Kinetic theory of oxygen isotopic exchange between minerals and water. Geochimica et Cosmochimica Acta 51, 1099-1108.

Daëron, M., Guo, W., Eiler, J., Genty, D., Blamart, D., Boch, R., Drysdale, R., Maire, R., Wainer, K., Zanchetta, G., 2011. ${ }^{13} \mathrm{C}^{18} \mathrm{O}$ clumping in speleothems: Observations from 
natural caves and precipitation experiments. Geochimica et Cosmochimica Acta 75,

Dansgaard, W., 1964. Stable isotopes in precipitation. Tellus 16, 436-468.

Defliese, W.F., Hren, M.T., Lohmann, K.C., 2015. Compositional and Temperature Effects of Phosphoric Acid Fractionation on $\Delta 47$ Analysis and Implications for Discrepant Calibrations. Chemical Geology.

Degens, E.T., Epstein, S., 1962. Relationship between $\mathrm{O}^{18} / \mathrm{O}^{16}$ ratios in coexisting carbonates, cherts, and diatomites: geological notes. AAPG Bulletin 46, 534-542.

Dennis, K.J., Affek, H.P., Passey, B.H., Schrag, D.P., Eiler, J.M., 2011. Defining an absolute reference frame for 'clumped' isotope studies of $\mathrm{CO}_{2}$. Geochimica et Cosmochimica Acta 75, 7117-7131.

Dennis, K.J., Schrag, D.P., 2010. Clumped isotope thermometry of carbonatites as an indicator of diagenetic alteration. Geochimica et Cosmochimica Acta 74, 4110-4122.

Eagle, R., Eiler, J.M., Tripati, A.K., Ries, J., Freitas, P., Hiebenthal, C., Wanamaker, A., Taviani, M., Elliot, M., Marenssi, S., 2013. The influence of temperature and seawater carbonate saturation state on ${ }^{13} \mathrm{C}-{ }^{18} \mathrm{O}$ bond ordering in bivalve mollusks.

Eagle, R.A., Schauble, E.A., Tripati, A.K., Tütken, T., Hulbert, R.C., Eiler, J.M., 2010. Body temperatures of modern and extinct vertebrates from ${ }^{13} \mathrm{C}-{ }^{18} \mathrm{O}$ bond abundances in bioapatite. Proceedings of the National Academy of Sciences 107, 10377.

Eagle, R.A., Tütken, T., Martin, T.S., Tripati, A.K., Fricke, H.C., Connely, M., Cifelli, R.L., Eiler, J.M., 2011. Dinosaur body temperatures determined from isotopic $\left({ }^{13} \mathrm{C}\right.$ ${ }^{18} \mathrm{O}$ ) ordering in fossil biominerals. Science 333, 443.

Eiler, J.M., 2007. "Clumped-isotope" geochemistry - The study of naturally-occurring, multiply-substituted isotopologues. Earth and Planetary Science Letters 262, 309327.

Eiler, J.M., 2011. Paleoclimate reconstruction using carbonate clumped isotope thermometry. Quaternary Science Reviews 30, 3575-3588.

Eiler, J.M., 2013. The isotopic anatomies of molecules and minerals. Annual Review of Earth and Planetary Sciences 41, 411-441.

Eiler, J.M., Schauble, E., 2004. ${ }^{18} \mathrm{O}^{13} \mathrm{C}^{16} \mathrm{O}$ in Earth's atmosphere. Geochimica et Cosmochimica Acta 68, 4767-4777.

Epstein, S., Buchsbaum, R., Lowenstam, H.A., Urey, H.C., 1953. Revised carbonatewater isotopic temperature scale. Geological Society of America Bulletin 64, 13151325.

Epstein, S., Mayeda, T., 1953. Variation of $\mathrm{O}^{18}$ content of waters from natural sources. Geochimica et Cosmochimica Acta 4, 213-224.

Ferry, J.M., Passey, B.H., Vasconcelos, C., Eiler, J.M., 2011. Formation of dolomite at $40-80^{\circ} \mathrm{C}$ in the Latemar carbonate buildup, Dolomites, Italy, from clumped isotope thermometry. Geology 39, 571-574.

Finnegan, S., Bergmann, K., Eiler, J.M., Jones, D.S., Fike, D.A., Eisenman, I., Hughes, N.C., Tripati, A.K., Fischer, W.W., 2011. The magnitude and duration of Late Ordovician-Early Silurian glaciation. Science 331, 903.

Gammelsrød, T., Bartholomae, C., Boyer, D., Filipe, V., O'Toole, M., 1998. Intrusion of warm surface water along the Angolan-Namibian coast in February-March 1995: the 1995 Benguela Niño. South African Journal of Marine Science 19, 41-56. 
Ghosh, P., Adkins, J., Affek, H., Balta, B., Guo, W., Schauble, E.A., Schrag, D., Eiler, J.M., 2006. ${ }^{13} \mathrm{C}-{ }^{18} \mathrm{O}$ bonds in carbonate minerals: A new kind of paleothermometer. Geochimica et Cosmochimica Acta 70, 1439-1456.

Glenn, C.R., Arthur, M.A., 1988. Petrology and major element geochemistry of Peru margin phosphorites and associated diagenetic minerals: Authigenesis in modern organic-rich sediments. Marine Geology 80, 231-267.

Gregory, R.T., Criss, R.E., Taylor Jr, H.P., 1989. Oxygen isotope exchange kinetics of mineral pairs in closed and open systems: Applications to problems of hydrothermal alteration of igneous rocks and Precambrian iron formations. Chemical Geology 75, $1-42$.

Guo, W., Mosenfelder, J.L., Goddard III, W.A., Eiler, J.M., 2009. Isotopic fractionations associated with phosphoric acid digestion of carbonate minerals: Insights from firstprinciples theoretical modeling and clumped isotope measurements. Geochimica et Cosmochimica Acta 73, 7203-7225.

Henkes, G.A., Passey, B.H., Grossman, E.L., Shenton, B.J., Pérez-Huerta, A., Yancey, T.E., 2014. Temperature limits for preservation of primary calcite clumped isotope paleotemperatures. Geochimica et Cosmochimica Acta 139, 362-382.

Henkes, G.A., Passey, B.H., Wanamaker, A.D., Grossman, E.L., Ambrose, W.G., Carroll, M.L., 2013. Carbonate clumped isotope compositions of modern marine mollusk and brachiopod shells. Geochimica et Cosmochimica Acta.

Hiatt, E.E., Budd, D.A., 2001. Sedimentary phosphate formation in warm shallow waters: new insights into the palaeoceanography of the Permian Phosphoria Sea from analysis of phosphate oxygen isotopes. Sedimentary Geology 145, 119-133.

Huntington, K., Eiler, J., Affek, H., Guo, W., Bonifacie, M., Yeung, L., Thiagarajan, N., Passey, B., Tripati, A., Daëron, M., 2009. Methods and limitations of 'clumped' $\mathrm{CO}_{2}$ isotope $\left(\Delta_{47}\right)$ analysis by gas-source isotope ratio mass spectrometry. Journal of Mass Spectrometry 44, 1318-1329.

Jaffrés, J.B.D., Shields, G.A., Wallmann, K., 2007. The oxygen isotope evolution of seawater: A critical review of a long-standing controversy and an improved geological water cycle model for the past 3.4 billion years. Earth-Science Reviews 83, 83-122.

Jaisi, D.P., Blake, R.E., 2010. Tracing sources and cycling of phosphorus in Peru Margin sediments using oxygen isotopes in authigenic and detrital phosphates. Geochimica et Cosmochimica Acta 74, 3199-3212.

Jarvis, I., 1992. Sedimentology, geochemistry and origin of phosphatic chalks: the Upper Cretaceous deposits of NW Europe. Sedimentology 39, 55-97.

Karhu, J., Epstein, S., 1986. The implication of the oxygen isotope records in coexisting cherts and phosphates. Geochimica et Cosmochimica Acta 50, 1745-1756.

Kasting, J.F., Howard, M.T., Wallmann, K., Veizer, J., Shields, G., Jaffrés, J., 2006. Paleoclimates, ocean depth, and the oxygen isotopic composition of seawater. Earth and Planetary Science Letters 252, 82-93.

Kastner, M., Garrison, R., Kolodny, Y., Reimers, C., Shemesh, A., 1990. Coupled changes of oxygen isotopes in $\mathrm{PO}_{4}{ }^{3-}$ and $\mathrm{CO}_{3}{ }^{2-}$ in apatite, with emphasis on the Monterey Formation, California. Phosphate Deposits of the World 3, 312-324.

Killingley, J.S., 1983. Effects of diagenetic recrystallization on ${ }^{18} \mathrm{O} /{ }^{16} \mathrm{O}$ values of deep-sea sediments. Nature 301, 594-597. 
Kim, S.T., O'Neil, J.R., 1997. Equilibrium and nonequilibrium oxygen isotope effects in

Kluge, T., John, C.M., Jourdan, A.-L., Davis, S., Crawshaw, J., 2015. Laboratory calibration of the calcium carbonate clumped isotope thermometer in the $25-250^{\circ} \mathrm{C}$ temperature range. Geochimica et Cosmochimica Acta 157, 213-227.

Knauth, L.P., Epstein, S., 1976. Hydrogen and oxygen isotope ratios in nodular and bedded cherts. Geochimica et Cosmochimica Acta 40, 1095-1108.

Koch, P.L., Tuross, N., Fogel, M.L., 1997. The effects of sample treatment and diagenesis on the isotopic integrity of carbonate in biogenic hydroxylapatite. Journal of Archaeological Science 24, 417-430.

Kohn, M.J., Cerling, T.E., 2002. Stable isotope compositions of biological apatite, in: Kohn, M.J., Rakovan, J.M., Huges, J.M. (Eds.), Phosphates-Geochemical, Geobiological, and Materials Importance. Mineralogical Society of America, Washington, DC, pp. 455-488.

Kolodny, Y., Kaplan, I., 1970. Carbon and oxygen isotopes in apatite $\mathrm{CO}_{2}$ and coexisting calcite from sedimentary phosphorite. Journal of Sedimentary Research 40, 954-959.

Kolodny, Y., Luz, B., 1991. Oxygen isotopes in phosphates of fossil fish-Devonian to Recent. Stable isotope geochemistry: A tribute to Samuel Epstein 3, 105-119.

Kolodny, Y., Luz, B., Navon, O., 1983. Oxygen isotope variations in phosphate of biogenic apatites, I. Fish bone apatite-rechecking the rules of the game. Earth and Planetary Science Letters 64, 398-404.

Kolodny, Y., Luz, B., Sander, M., Clemens, W., 1996. Dinosaur bones: Fossils or pseudomorphs? The pitfalls of physiology reconstruction from apatitic fossils. Palaeogeography, Palaeoclimatology, Palaeoecology 126, 161-171.

Land, L.S., 1995. Comment on "Oxygen and carbon isotopic composition of Ordovician brachiopods: Implications for coeval seawater" by H. Qing and J. Veizer. Geochimica et Cosmochimica Acta 59, 2843-2844.

Lasaga, A.C., 1989. A new approach to isotopic modeling of the variation of atmospheric oxygen through the Phanerozoic. Am. J. Sci 289.

Lawrence, J., Gieskes, J., 1981. Constraints on water transport and alteration in the oceanic crust from the isotopic composition of pore water. Journal of Geophysical Research: Solid Earth (1978-2012) 86, 7924-7934.

Lécuyer, C., Allemand, P., 1999. Modelling of the oxygen isotope evolution of seawater: Implications for the climate interpretation of the $\delta^{18} \mathrm{O}$ of marine sediments. Geochimica et Cosmochimica Acta 63, 351-361.

Lécuyer, C., Amiot, R., Touzeau, A., Trotter, J., 2013. Calibration of the phosphate $\delta^{18} \mathrm{O}$ thermometer with carbonate-water oxygen isotope fractionation equations. Chemical Geology.

Lécuyer, C., Balter, V., Martineau, F., Fourel, F., Bernard, A., Amiot, R., Gardien, V., Otero, O., Legendre, S., Panczer, G., 2010. Oxygen isotope fractionation between apatite-bound carbonate and water determined from controlled experiments with synthetic apatites precipitated at $10-37^{\circ}$ C. Geochimica et Cosmochimica Acta 74, 2072-2081.

Lécuyer, C., Grandjean, P., Barrat, J.-A., Nolvak, J., Emig, C., Paris, F., Robardet, M., 1998. $\delta^{18} \mathrm{O}$ and REE contents of phosphatic brachiopods: A comparison between 
modern and lower Paleozoic populations. Geochimica et Cosmochimica Acta 62,

Lécuyer, C., Grandjean, P., Emig, C., 1996. Determination of oxygen isotope fractionation between water and phosphate from living lingulids: Potential application to palaeoenvironmental studies. Palaeogeography, Palaeoclimatology, Palaeoecology 126, 101-108.

Longinelli, A., 1984. Oxygen isotopes in mammal bone phosphate: A new tool for paleohydrological and paleoclimatological research? Geochimica et Cosmochimica Acta 48, 385-390.

Longinelli, A., Nuti, S., 1968. Oxygen isotopic composition of phosphorites from marine formations. Earth and Planetary Science Letters 5, 13-16.

Longinelli, A., Nuti, S., 1973. Revised phosphate-water isotopic temperature scale. Earth and Planetary Science Letters 19,373-376.

Longinelli, A., Wierzbowski, H., Di Matteo, A., 2003. $\delta^{18} \mathrm{O}\left(\mathrm{PO}_{4}{ }^{3-}\right)$ and $\delta^{18} \mathrm{O}\left(\mathrm{CO}_{3}{ }^{2-}\right)$ from belemnite guards from Eastern Europe: Implications for palaeoceanographic reconstructions and for the preservation of pristine isotopic values. Earth and Planetary Science Letters 209, 337-350.

Luz, B., Kolodny, Y., Horowitz, M., 1984a. Fractionation of oxygen isotopes between mammalian bone-phosphate and environmental drinking water. Geochimica et Cosmochimica Acta 48, 1689-1693.

Luz, B., Kolodny, Y., Kovach, J., 1984b. Oxygen isotope variations in phosphate of biogenic apatites, III. Conodonts. Earth and Planetary Science Letters 69, 255-262.

McArthur, J., Benmore, R., Coleman, M., Soldi, C., Yeh, H.-W., O'Brien, G., 1986. Stable isotopic characterisation of francolite formation. Earth and Planetary Science Letters 77, 20-34.

McArthur, J., Coleman, M., Bremner, J., 1980. Carbon and oxygen isotopic composition of structural carbonate in sedimentary francolite. Journal of the Geological Society 137, 669-673.

McArthur, J., Herczeg, A., 1990. Diagenetic stability of the isotopic composition of phosphate-oxygen: palaeoenvironmental implications. Geological Society, London, Special Publications 52, 119-124.

McArthur, J., Sahami, A., Thirlwall, M., Hamilton, P., Osborn, A., 1990. Dating phosphogenesis with strontium isotopes. Geochimica et Cosmochimica Acta 54, 1343-1351.

McCrea, J.M., 1950. On the isotopic chemistry of carbonates and a paleotemperature scale. Journal of Chemical Physics 18, 849-857.

Miller, K.G., Fairbanks, R.G., Mountain, G.S., 1987. Tertiary oxygen isotope synthesis, sea level history, and continental margin erosion. Paleoceanography 2, 1-19.

Muehlenbachs, K., 1986. Alteration of the oceanic crust and the ${ }^{18} \mathrm{O}$ history of seawater. Reviews in Mineralogy and Geochemistry 16, 425-444.

O'Neil, J.R., Clayton, R.N., Mayeda, T.K., 1969. Oxygen isotope fractionation in divalent metal carbonates. Univ. of Chicago.

Passey, B., Henkes, G., 2012. Carbonate clumped isotope bond reordering and geospeedometry. Earth and Planetary Science Letters 351-352, 223-236. 
1353 Passey, B.H., Cerling, T.E., Levin, N.E., 2007. Temperature dependence of oxygen

1354 isotope acid fractionation for modern and fossil tooth enamels. Rapid

1355

1356

1357

1358

1359

1360

1361

1362

1363

1364

1365

1366

1367

1368

1369

1370

1371

1372

1373

1374

1375

1376

1377

1378

1379

1380

1381

1382

1383

1384

1385

1386

1387

1388

1389

1390

1391

1392

1393

1394

1395

1396

1397

1398 communications in mass spectrometry 21, 2853-2859.

Passey, B.H., Levin, N.E., Cerling, T.E., Brown, F.H., Eiler, J.M., 2010. Hightemperature environments of human evolution in East Africa based on bond ordering in paleosol carbonates. Proceedings of the National Academy of Sciences 107, 11245.

Petersen, S., Schrag, D., 2015. Antarctic ice growth before and after the Eocene Oligocene transition: New estimates from clumped isotope paleothermometry. Paleoceanography 30, 1305-1317.

Pucéat, E., Joachimski, M.M., Bouilloux, A., Monna, F., Bonin, A., Motreuil, S., Morinière, P., Hénard, S., Mourin, J., Dera, G., 2010. Revised phosphate-water fractionation equation reassessing paleotemperatures derived from biogenic apatite. Earth and Planetary Science Letters 298, 135-142.

Reeves, D., Rothman, D.H., 2013. Age dependence of mineral dissolution and precipitation rates. Global Biogeochemical Cycles 27, 906-919.

Sadaqah, R.M., Abed, A.M., Grimm, K.A., Pufahl, P.K., 2007. Oxygen and carbon isotopes in Jordanian phosphorites and associated fossils. Journal of Asian Earth Sciences 29, 803-812.

Saenger, C., Affek, H.P., Felis, T., Thiagarajan, N., Lough, J.M., Holcomb, M., 2012. Carbonate clumped isotope variability in shallow water corals: Temperature dependence and growth-related vital effects. Geochimica et Cosmochimica Acta 99, 224-242.

Schauble, E.A., Ghosh, P., Eiler, J.M., 2006. Preferential formation of ${ }^{13} \mathrm{C}-{ }^{18} \mathrm{O}$ bonds in carbonate minerals, estimated using first-principles lattice dynamics. Geochimica et Cosmochimica Acta 70, 2510-2529.

Schrag, D.P., DePaolo, D.J., Richter, F.M., 1992. Oxygen isotope exchange in a twolayer model of oceanic crust. Earth and Planetary Science Letters 111, 305-317.

Schrag, D.P., DePaolo, D.J., Richter, F.M., 1995. Reconstructing past sea surface temperatures: Correcting for diagenesis of bulk marine carbonate. Geochimica et Cosmochimica Acta 59, 2265-2278.

Sharp, Z.D., Atudorei, V., Furrer, H., 2000. The effect of diagenesis on oxygen isotope ratios of biogenic phosphates. American Journal of Science 300, 222-237.

Shemesh, A., 1990. Crystallinity and diagenesis of sedimentary apatites. Geochimica et Cosmochimica Acta 54, 2433-2438.

Shemesh, A., Kolodny, Y., Luz, B., 1983. Oxygen isotope variations in phosphate of biogenic apatites, II. Phosphorite rocks. Earth and Planetary Science Letters 64, $405-$ 416.

Shemesh, A., Kolodny, Y., Luz, B., 1988. Isotope geochemistry of oxygen and carbon in phosphate and carbonate of phosphorite francolite. Geochimica et Cosmochimica Acta 52, 2565-2572.

Silverman, S.R., Fuyat, R.K., Weiser, J.D., 1952. Quantitative determination of calcite associated with carbonate-bearing Apatites. American Mineralogist 37, 211-222.

Stern, M.J., Spindel, W., Monse, E., 1968. Temperature dependences of isotope effects. The Journal of Chemical Physics 48, 2908.

Stolper, D.A., 2014. New insights into the formation and modification of carbonatebearing minerals and methane gas in geological systems using multiply substituted 

isotoplogues, Geological and Planetary Sciences. California Institute of Technology, 
1445 paleothermometer using calcites of various origins. Geochimica et Cosmochimica 1446 Acta 141, 127-144.

1447 Wang, Z., Schauble, E.A., Eiler, J.M., 2004. Equilibrium thermodynamics of multiply

1448 substituted isotopologues of molecular gases. Geochimica et Cosmochimica Acta 68, 1449 4779-4797.

1450 Wenzel, B., Lécuyer, C., Joachimski, M.M., 2000. Comparing oxygen isotope records of 1451 silurian calcite and phosphate $-\delta^{18} \mathrm{O}$ compositions of brachiopods and conodonts. 1452 Geochimica et Cosmochimica Acta 64, 1859-1872.

1453 Zaarur, S., Affek, H.P., Brandon, M.T., 2013. A revised calibration of the clumped $1454 \quad$ isotope thermometer. Earth and Planetary Science Letters 382, 47-57.

1455 Zazzo, A., Lécuyer, C., Mariotti, A., 2004. Experimentally-controlled carbon and oxygen 1456 isotope exchange between bioapatites and water under inorganic and microbially1457 mediated conditions. Geochimica et Cosmochimica Acta 68, 1-12.

1458 Zhang, Y., 1994. Reaction kinetics, geospeedometry, and relaxation theory. Earth and 1459

1460 planetary science letters 122, 373-391.

1461 


\section{Figurea1}
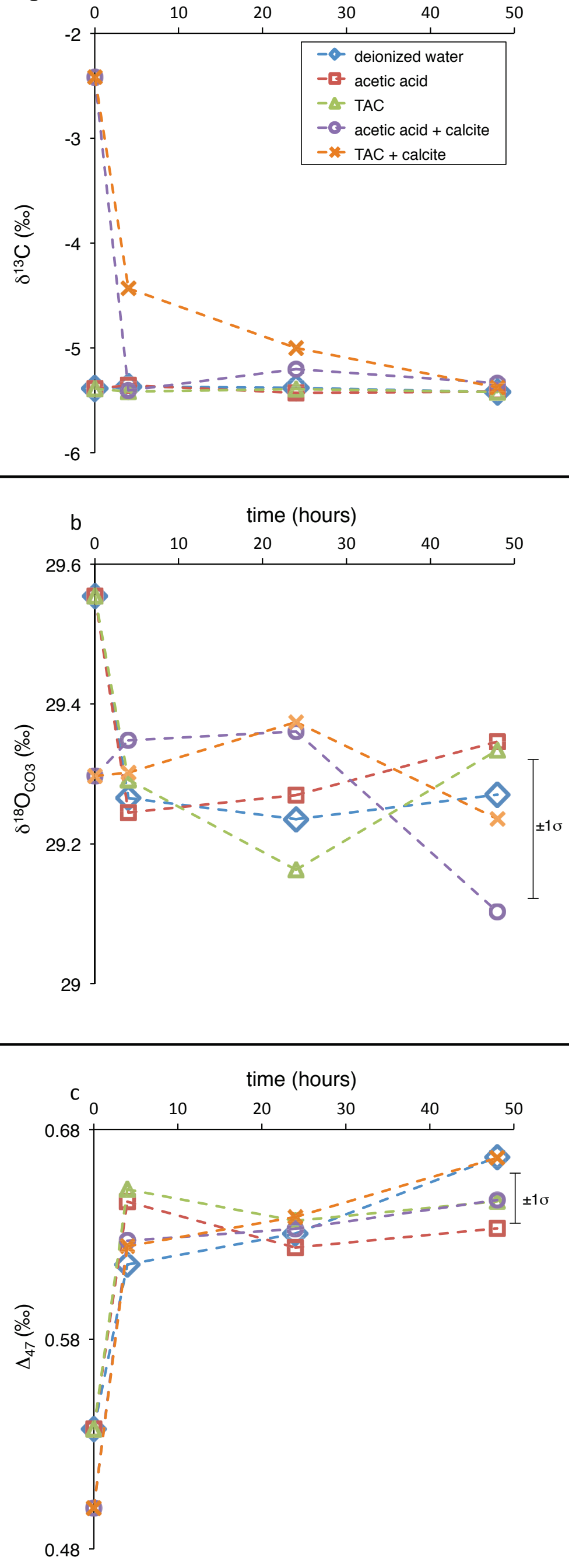

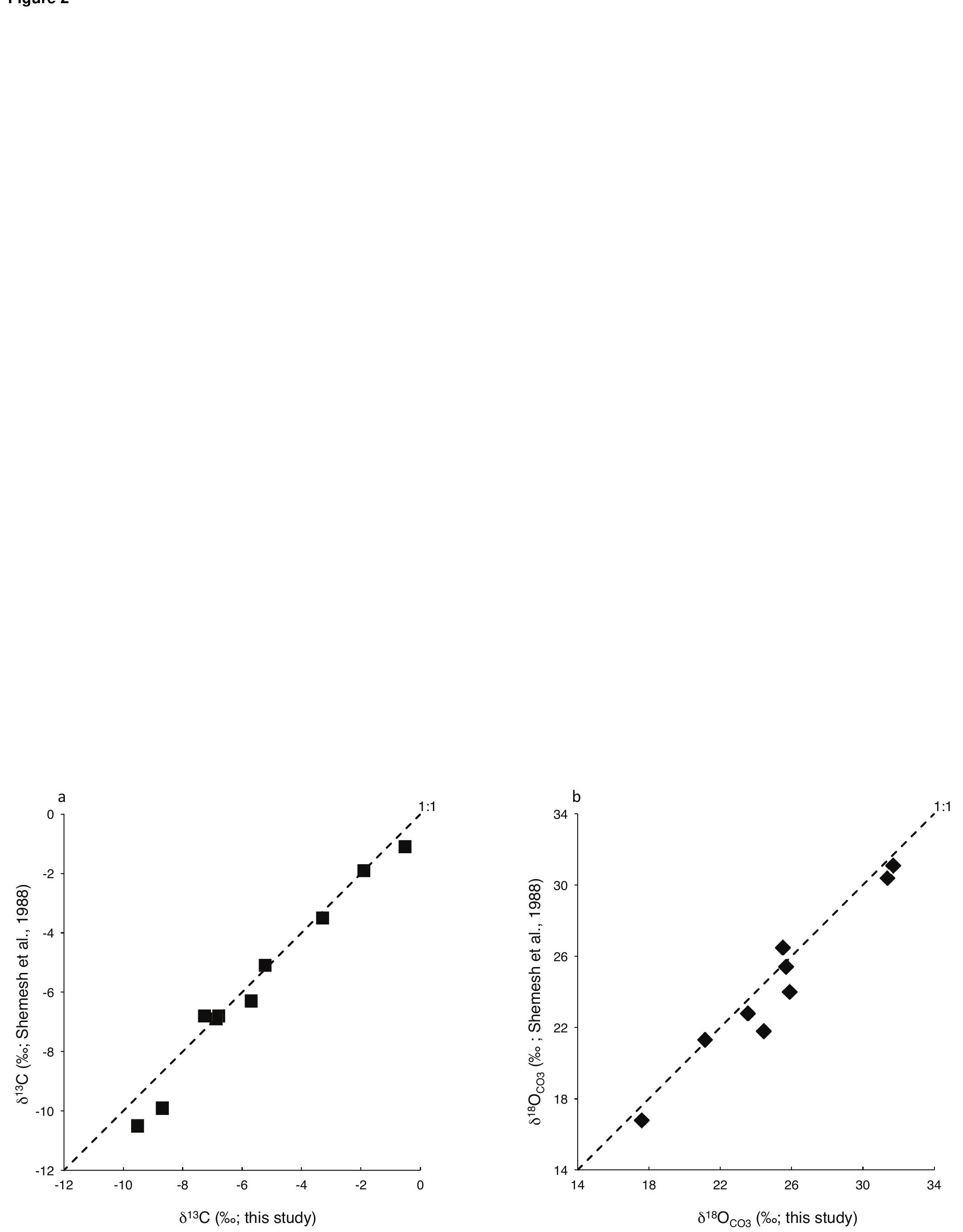

Figure 2

$$
\text { (1) }
$$

, 

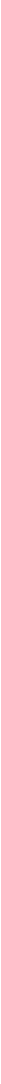


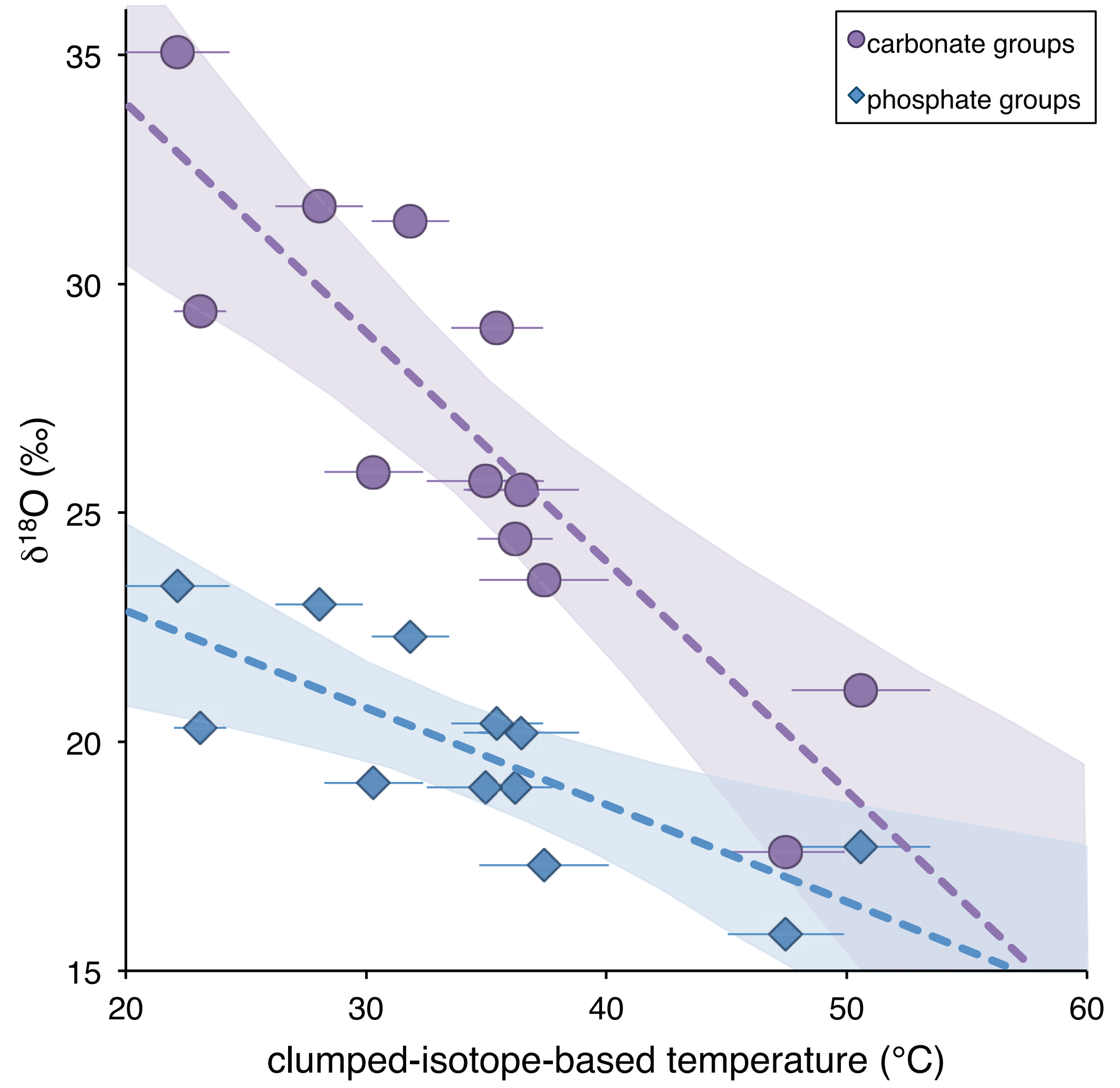


Figure 6

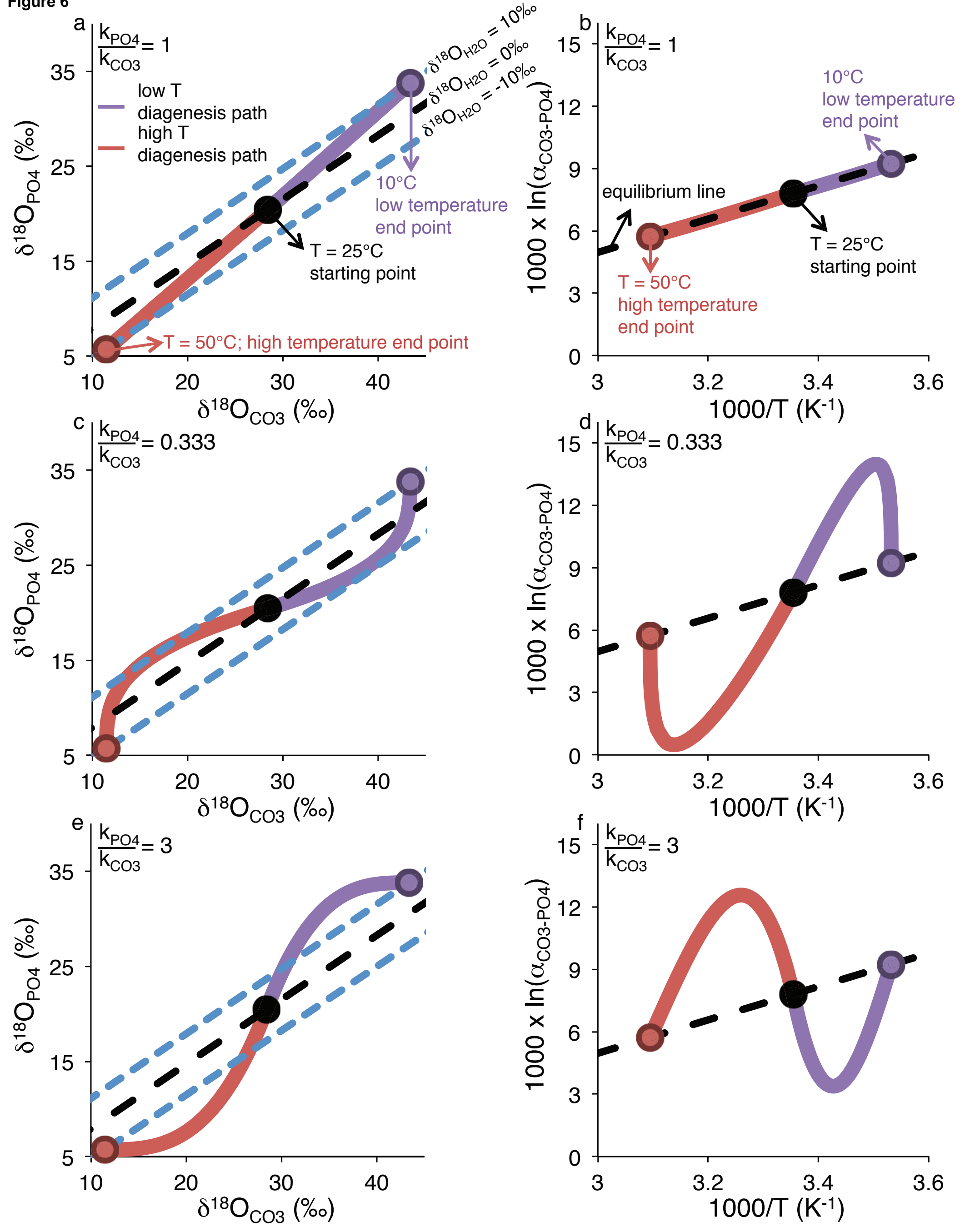

